\title{
Explosive Performance Assessment of Buried Steel Pipeline
}

\author{
Seyed-Mohammad Seyed-Kolbadi, ${ }^{1}$ Mohammad Safi, ${ }^{2}$ Ayoub Keshmiri, ${ }^{3}$ \\ S. Mahdi S. Kolbadi ${ }^{D},{ }^{4}$ and Masoud Mirtaheri ${ }^{4}$ \\ ${ }^{1}$ Department of Civil Engineering, Branch of Shahid Chamran, Technical and Vocational University of Golestan, Gorgan, Iran \\ ${ }^{2}$ Shahid Beheshti University, Department of Civil and Environmental Engineering, Tehran, Iran \\ ${ }^{3}$ Department of Civil Engineering, Branch of Aliabad, University of Golestan, Aliabad, Iran \\ ${ }^{4}$ Department of Civil Engineering, KN Toosi University of Technology, Tehran, Iran
}

Correspondence should be addressed to S. Mahdi S. Kolbadi; mahdi_kolbadi@sina.kntu.ac.ir

Received 13 December 2020; Revised 23 March 2021; Accepted 16 April 2021; Published 5 May 2021

Academic Editor: Edén Bojórquez

Copyright ( 2021 Seyed-Mohammad Seyed-Kolbadi et al. This is an open access article distributed under the Creative Commons Attribution License, which permits unrestricted use, distribution, and reproduction in any medium, provided the original work is properly cited.

\begin{abstract}
It is so important to consider the passive defense problem in any places there have been attacks by varies kinds of military threats and terrorists. It is certain that social security is related to overcoming on these perils and protection from country. Vital facilities are one of examples that should be protected. Vital facilities include roads, bridges, transmission lines, and telecom and media network. With attention to the intense dependent to export and transmit of oil and gas and with consideration of this point that many places are full of gas and oil resource, the protection of these lines is very important. In recent years, occurrence of varies kinds of terrorist accidents in relation to important structures in all the world causes that the explosion loads have special attention. Explosion can generate much damage with vibration in vast soil media. Thus, it is important to predict the dynamic impact load and its treatment response. With attention to regardable development of numerical methods in recent decades, it is possible to investigate the explosion effects on surface and underground structures. In this research, the newest applied method modeling of the explosion phenomenon has been investigated and comprehensive information has been earned. In this investigation, problem of explosion wave's propagation effects on buried pipes simulated by ABAQUS/CAE 6.10-1 was studied based on the finite element method. Surface explosion effects on gas buried pipe lines and their dynamic response have been investigated depending on properties and their characteristics. The variation of buried pipe depth effects and variation effects in soil properties around pipe in different cases has been considered, and the results are here. The results showed that in buried pipes under surface explosions, displacements, major stresses, and strains decrease in clay, dense, and loose sands with increase of buried depth. These results obtain that because of increase of closuring of pipes in soil when internal friction angle increases for a kind of soil, the stress on pipe rim will decrease also. It was also observed that the pipe performance in clay and loose sands is better than that in compacted sand, respectively.
\end{abstract}

\section{Introduction}

Vital arteries include roads, stairs, tunnels, transmission lines (water, oil, and gas), and communication and media networks. If one of the vital arteries is damaged, malfunctioning, urban activities, or relief work will be paralyzed during the crisis, thus increasing the loss of life and property. If the threatening factors of vital arteries are divided into two categories, natural and human factors, earthquakes, and explosions can be mentioned as examples of them, respectively. Over recent years, various terrorist incidents on important structures worldwide have caused special attention to be paid to explosive devices, in large cities that use underground spaces for highways, tunnels, and underground pipes. Therefore, it is essential to predict the dynamic impact loads and investigate the behavioral response of the structures. The reliable and economical design of structures requires a better understanding of the sophisticated and practical parameters of these structures. Due to the necessity and importance of these vital arteries, and if there is proper 
information, we will be able to predict the possible effects of the explosion on them according to the specifications of the existing pipelines; in addition, if necessary, we should take steps to cure them. Also, with such information, the design of pipelines in the future can be more precise and safer, and the considerations related to the passive defense of vital arteries can be considered more effective. In recent years, there have been significant advances in developing numerical and laboratory methods for studying such systems. In the present study, comprehensive information will be obtained by examining the latest methods used to model the explosion phenomenon and the responses obtained from underground structures.

1.1. Modeling the Behavior of Materials. The simulation of the nonlinear part of the soil behavior has been performed using the modified Drucker-Prager plastic processor (cap) model. We also need to specify the level of yield, flow $\omega$ law, and hardening law. The rupture level of the Drucker-Prager is obtained from the following equation [1]:

$$
F_{s}=t-p \tan \beta-d=0 .
$$

$\beta\left(\theta, f_{i}\right)$ and $d\left(\theta, f_{i}\right)$ represent the angle of friction of the material and its bond, respectively, and can be defined as a function of temperature, $\theta$, and others. $T$ and $P$ are equivalent to the amount of deviation stress and compressive stress, respectively [2] Table 1.

According to Iran's 2800 regulations, the selected base soil is type IV, which is considered soft soil. Then, by changing the effective parameters in the interaction and response of the structure, about 50 analyses with different parameters have been performed, which have been then displayed under different diagrams.

In addition, the used mechanical properties for simulation of steel pipeline can be found in Figure 1.

\section{Numerical Solution Methods}

2.1. Motion Equations. The most common solution to the problem of soil-structure interaction is the analysis based on the substructure method. In this method, the linear problem of soil-structure interaction is separated into a series of simpler subproblems, and then the results are combined using the principle of superposition. In the substructure isolation method [3], the whole soil-structure system, shown in Figure 2, is divided into three substructures. Substructure I includes the free area of the structure, substructure II includes the volume of soil removed, and substructure III includes the surface structure and its foundation. In the substructure isolation method, it is assumed that soil and structure interaction occurs only at the common boundary of the substructures (soil contact surface). The equation of motion of the substructures shown in Figure 2 can be written in matrix form (1). For harmonic excitation, mixed force vectors, and frequency displacement, the equation of motion for the soil-structure interaction system will be (8), when indices I, II, and III are related to the three substructures and indices $i, w$, and $s$, respectively, are related to the degrees of freedom corresponding to the nodes at the boundary of soil and structure, removed soil volume, and the upper part of the structure (Figure 3):

$$
\begin{gathered}
{[M]\{\tilde{u}\}+[K]\{\hat{u}\}=\{\hat{Q}\},} \\
{\left[\begin{array}{ccc}
C_{i i}^{I I}-C_{i i}^{I I}+X_{i i} & -C_{i w}^{I I} & C_{i s}^{I I I} \\
-C_{w i}^{I I} & -C_{w w}^{I I} & 0 \\
-C_{s i}^{I I I} & 0 & C_{s s}^{I I I}
\end{array}\right]\left\{\begin{array}{c}
u_{i} \\
u_{w} \\
u_{s}
\end{array}\right\}=\left\{\begin{array}{c}
X_{i i} u_{i} \\
0 \\
0
\end{array}\right\} .}
\end{gathered}
$$

2.2. The Site Response. For solving the problem of the construction response, it is necessary to make and solve the problem of eigenvalue for the model. In calculations related to volumetric waves from the submatrices calculated from the characteristics of each layer, they are used to form eigenvalue equations. In Kiran and Manoj's study [4], based on the construction model with horizontal layers and the assumption of linear deformation changes within each layer, the eigenvalue problem can be divided into two separate algebraic eigenvalue problems. These include the Riley wave, and the other one is for the movement of the Love wave. The equation of the eigenvalue for the motion of the Riley wave can be written in the following matrix form using the isolated soil model. There are two degrees of freedom in this model at each boundary between the two layers; thus, each $n$-layer system will have $2 n$ degrees of freedom. In the previous equation, $\omega$ is the mode vibration angular frequency, $K$ is the eigenvalue, and $\{V\}$ is the corresponding $2 n$ component eigenvector. The dimensions of the matrices $[A],[B],[G]$, and $[M]$ are $2 n \times 2 n$, and these matrices are obtained by the summation of the matrices related to sublayers. If the depth of the $j$ layer from the top is $h_{j}$ and also the volumetric mass, shear modulus, and its constant are $\rho_{j}, G_{j}$, and $\lambda_{j}$, respectively, these matrices will be as follows:

Eigenvalue equations: 


$$
\begin{aligned}
\left([A] K^{2}+i[B] K+[G]-\omega^{2}[M]\right)\{V\} & =0 \\
{\left[A_{j}\right] } & =\frac{h_{j}}{6}\left[\begin{array}{ccccc}
2\left(\lambda_{j}+2 G_{j}\right) & 0 & \left(\lambda_{j}+2 G_{j}\right) & 0 \\
0 & 2 G_{j} & 0 & G_{j} \\
\left(\lambda_{j}+2 G_{j}\right) & 0 & 2\left(\lambda_{j}+2 G_{j}\right) & 0 \\
& 0 & G_{j} & 0 & 2 G_{j}
\end{array}\right], \\
{\left[M_{j}\right]^{[l]}=} & \frac{\rho_{j} h_{j}}{6}\left[\begin{array}{cccc}
1 & 0 & 0 & 0 \\
0 & 1 & 0 & 0 \\
0 & 0 & 1 & 0 \\
0 & 0 & 0 & 1
\end{array}\right] .
\end{aligned}
$$

Eigenvalue equation using numerical techniques:

$$
\begin{aligned}
& \left([A] K^{2}+i[B] K+[G]-\omega^{2}[M]\right)\{V\}=0, \\
& {\left[G_{j}\right]=\frac{1}{h_{j}}\left[\begin{array}{cccc}
G_{j} & 0 & G_{j} & 0 \\
0 & \left(\lambda_{j}+2 G_{j}\right) & 0 & -\left(\lambda_{j}+2 G_{j}\right) \\
-G_{j} & 0 & G_{j} & 0 \\
0 & -\left(\lambda_{j}+2 G_{j}\right) & 0 & \left(\lambda_{j}+2 G_{j}\right)
\end{array}\right],} \\
& {\left[A_{j}\right]=h_{j} G_{j}\left[\begin{array}{ll}
\frac{1}{3} & \frac{1}{6} \\
\frac{1}{6} & \frac{1}{3}
\end{array}\right],} \\
& {\left[G_{j}\right]=\frac{G_{j}}{h_{j}}\left[\begin{array}{cc}
1 & -1 \\
-1 & 1
\end{array}\right] \text {, }} \\
& {\left[M_{j}\right]^{[c]}=\frac{\rho_{j} h_{j}}{6}\left[\begin{array}{llll}
2 & 0 & 1 & 0 \\
0 & 2 & 0 & 1 \\
1 & 0 & 2 & 0 \\
0 & 1 & 0 & 2
\end{array}\right] \text {, }} \\
& {\left[M_{j}\right]^{(c)}=\frac{\rho_{j} h_{j}}{6}\left[\begin{array}{ll}
2 & 1 \\
1 & 2
\end{array}\right],} \\
& {\left[M_{j}\right]^{(l)}=\frac{\rho_{j} h_{j}}{2}\left[\begin{array}{ll}
1 & 0 \\
0 & 1
\end{array}\right] \text {. }}
\end{aligned}
$$




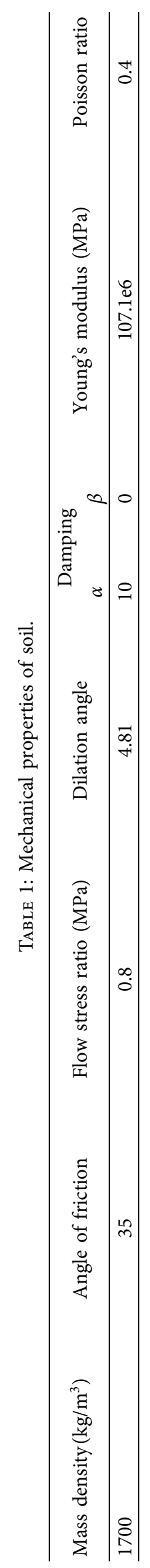




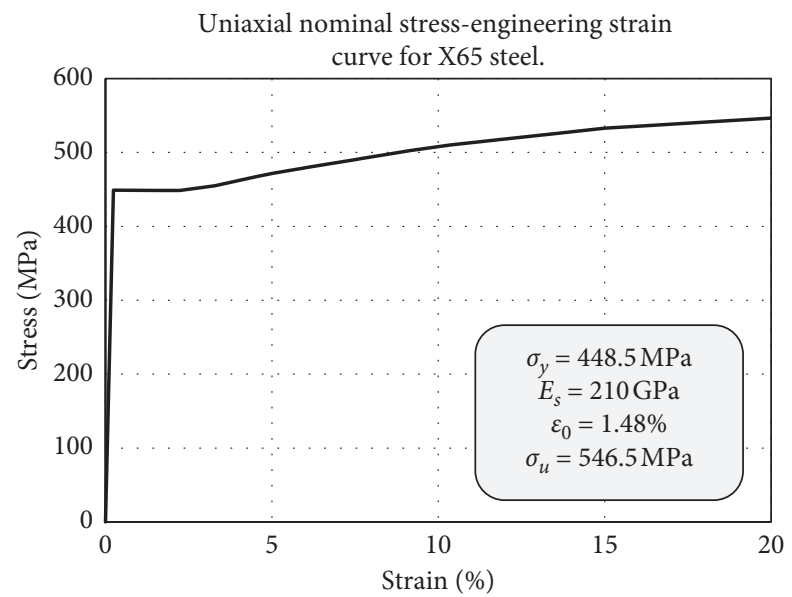

FIgURE 1: Mechanical properties of used wave-shaped connection in the FE numerical model.

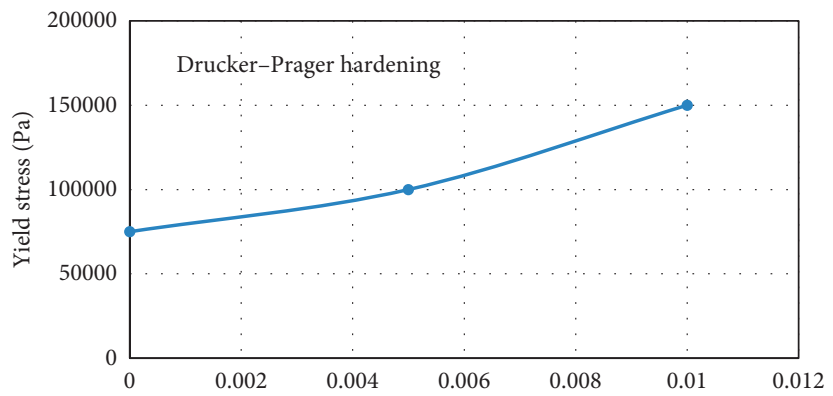

FIGURE 2: Drucker-Prager hardening model.

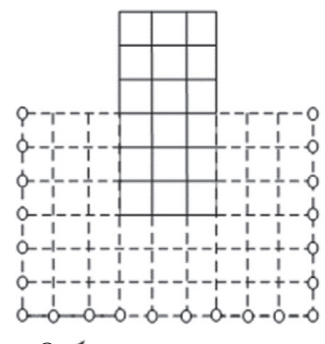

(a)

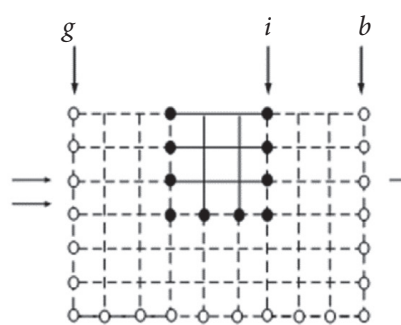

(b)

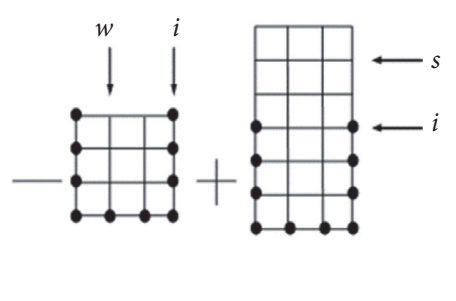

(c) (d)

FIGURE 3: Separation of infrastructures to make calculations more simple: (a) total, (b) substructure I, (c) substructure II, and (d) substructure III.

Matrices $\left[M_{j}\right]^{[c]}$ and $\left[M_{j}\right]^{[l]}$ are the continuous and concentrated mass matrices, respectively. Using the numerical techniques suggested by Was, equation (5) of the eigenvalue can be obtained. By solving the equation, $2 n$ Riley mode, as well as $2 n$ wavenumber, is obtained. These values will be used to calculate the conditions of energy-absorbing boundaries in wave deformation motions on the system model screen. Based on the layered soil model, the eigenvalue problem for the motion of the Love wave can be written in the following form. In this waveform, at the boundary of each layer, there is only one degree of freedom. The following matrices $[A],[G]$, and $[M]$ are derived from the following matrices.
Shi [5] wrote the equation of motion for SV inclined waves using the $n$-layer soil system. The equation of motion of the soil system, which is affected by SV waves, can be written as (18). Matrices $[A][G]$, and $[M]$ are obtained from the summation of the submatrices defined in equations (6) and (7). The matrix $[B]$ is obtained from the summation of the following submatrices, $\left[\bar{B}_{j}\right]$, defined as equation (19). If $M_{j}$ and $G_{j}$ are the binding and shear modulus of the $J$ layer, respectively, the vector $\left\{P_{b}\right\}$ is a two-component vector, which defines the load vector at the bottom of the layer (rock bed). From the solution of equation (7), the displacement vector $\{u\}$ is obtained. At any distance $x$, the free-field motion can be achieved using equation (7) and $\delta$ is the 
coefficient of modal participation that is calculated by applying the control motion at a point:

$\left([A] K^{2}+[\bar{B}] K+[G]-\omega^{2}[M]\right)\{u\}=\left\{\begin{array}{c}0 \\ P_{b}\end{array}\right\}$,

$$
\left[\bar{B}_{j}\right]=\frac{1}{2}\left[\begin{array}{cccc}
0 & \left(3 G_{j}-M_{j}\right) & 0 & -\left(G_{J}-M_{j}\right) \\
\left(3 G_{j}-M_{j}\right) & 0 & \left(G_{j}-M_{j}\right) & 0 \\
0 & \left(G_{j}-M_{j}\right) & 0 & \left(3 G_{j}-M_{j}\right) \\
-\left(G_{j}-M_{j}\right) & 0 & \left(3 G_{j}-M_{j}\right) & 0
\end{array}\right],
$$

$$
\{u(x)\}=\delta . \exp (-i k x) .
$$

The semi-infinite semispace can be modeled by two methods, variable depth and viscous boundary at the base. Substructure methods are valid only for linear analyses. However, soils exhibit nonlinear behavior depends on strain in response to dynamic loading. Nonlinear soil behavior can be considered using the equivalent linear method proposed by Syed and Idris [6] and others. In this way, soil nonlinear characteristics are estimated by equivalent linear characteristics, including shear modulus and damping coefficient.

2.3. The Impedance. In the substructure isolation method, the equations of motion of the SSI system, including the impedance matrix $\left[X_{f f}\right]$, are shown in equation (8). In this method, the impedance matrix is calculated only for the boundary nodes ( $i$ nodes in Figure 3 ). At each analysis frequency, the impedance matrix is calculated by the dynamic compliance matrix. In three-dimensional problems, estimating the dynamic compliance matrix is reduced to the problem of finding the horizontal layer system response to loading at the boundary of the layers. After calculating the elements of mass and stiffness matrices, the equation of motion becomes (9). When $\mathrm{C}$ is the dynamic stiffness matrix $\left(C=K-\omega^{2} M\right), R$ is the impedance matrix of the energy-absorbing boundaries. Indices $c$ and $p$ are related to the degrees of freedom on the boundary line and the model environment, and $u_{c}$ and $u_{p}$ are the corresponding displacement sizes. The displacement of the outer nodes of model $\mathrm{C}$ is obtained from equation (10), where the index $m$ is related to the Fourier harmonic degree. The vector under the coefficients of the modal participation depends on the $3 n$ mode of displacement of the $n$-layer soil system:

$$
\begin{aligned}
{\left[\begin{array}{cc}
C_{C C} & C_{C P} \\
C_{P C} & C_{P P}+R
\end{array}\right]\left\{\begin{array}{l}
u_{c} \\
u_{p}
\end{array}\right\} } & =\left\{\begin{array}{c}
Q_{c} \\
0
\end{array}\right\}, \\
\{u(r)\}_{m} & =[w(r)]_{m}\{\Delta\}_{m},
\end{aligned}
$$

$$
\{\Delta\}_{m}^{T}=\left\langle\alpha_{1}, \alpha_{2}, \ldots, \alpha_{3 n}\right\rangle .
$$

Furthermore, matrix $[W(r)]_{m}$ is a $3 n \times 3 n$ matrix that is a function of the radial distance from the axis of the model, the eigenvalue, the eigenvector, and the $m$ degree function from the second type of Stankovic functions [7]. Equation (11) is used with the modal participation vector to calculate the displacement at any point at an $r$ radius distance from the model axis. At any frequency of analysis, a dynamic compliance matrix is a $3 i \times 3 i$ matrix for a system with $i$ interactional nodes within the free field environment. The direct impedance calculation method demands to calculate the compliance matrix $\left[F_{f f}\right]$ for all the nodes involved. The impedance matrix $\left[X_{f f}\right]$ is then calculated by inverting the dynamic compliance matrix:

$$
\left[X_{f f}\right]=\left[F_{f f}\right]^{-1} .
$$

2.4. Structural Analysis. In this section, the structural and removed soil characteristics, used in the motion equation coefficient matrix equations (12), are calculated including the components $A, B$, and $T$. The removed soil and structure are modeled by standard finite element models, and then their dynamic characteristics are calculated. Within the soilstructure system, in the event of stable dynamic excitation, equation (12) is formed and dissolved at separate selected harmonic frequencies. In the case of harmonic excitation of results, the harmonic mixed conversion acceleration functions indicate the response of the whole system to the harmonic input motion at the control point. Transient motions, such as earthquakes, are analyzed using separated Fourier conversion technique. Utilizing these techniques, the base input motion that specified at $\mathrm{N}$ separate points is evenly distributed over the $T$ period. The final result is obtained after summation in the following way:

$$
\left\{\begin{array}{l}
u_{x}(t) \\
u_{f}(t)
\end{array}\right\}=\operatorname{Re} \sum_{j=0}^{(N / 2)}\left\{\begin{array}{l}
u_{x j} \\
u_{f j}
\end{array}\right\} \exp \left(i \omega_{j} t\right) .
$$


For a single harmonic input, $f$ separate values at $L$ intervals can be calculated by Fourier inverse converting over $D$. Complete solution demands to form a linear equation system, and then it is solved for all FFT frequencies. This procedure requires considerable time and computational work. A high-level frequency and also an efficient method can be utilized so that the mixed response range, $M$, and $Z$ are selected and calculated at several critical frequencies besides response values at other FFT frequencies. It can also be identified by interpolation [8].

2.5. Soil and Structure Interaction. Within studying the interaction problem, the dynamic response of the structure is affected by the interactions of the structure, the foundation, and the surrounding soil. There are two general substructural and direct methods available for analyzing interaction issues [9]. In the substructure method, the entire infinite environment is modeled; after calculating the soil impedance matrix, it will be appended to the dynamic stiffness of the structure. This process will make the problem more straightforward to figure out and more comfortable with calculating. Under the direct method, only a part of the soil environment, which is close to the structure, is modeled [9]. In this method, complex geometric shapes, changes in soil properties, and nonlinear behavior of the environment can be considered. Inside the analysis of the time domain, nonlinear behavior of the soil and structure materials can also be considered.

This study operates the conventional model in defining the interaction of contact surfaces, the Columbus friction model. The model has been applied using the contact element, which will be explained below. The Columbus friction model determines the frictional behavior between contact surfaces utilizing a friction coefficient $\mu$. The default coefficient of friction is zero, so the tangential displacement will be zero until the surface tension exceeds a critical value for shear stress, and this depends on the vertical contact compression and is defined according to the following equation:

$$
\tau_{\text {crit }}=\mu \rho,
$$

where $\mu$ implies the coefficient of friction and $\rho$ is the contact compression between the two surfaces. This equation determines the extreme value of shear stress for the contact surfaces involved in the collision. As long as the shear stress between them is equal to the frictional shear stress, the contact levels will not slide upon each other, as displayed in the following behavioral diagram (Figure 4).

Soil and structure interaction is significant, particularly for large and massive structures that have been built in soft soil. When affected by a dynamic load, a dynamic reaction of the soil and structure complex signifies a function of the dynamic characteristics, induced forces, and stimuli, and the dynamic model of the system which involved the dynamic model of the structure linking with the dynamic model of the environment. Interaction is a boundary value problem.

Therefore, it requires an infinite environment model; however, infinite modeling of the environment is not

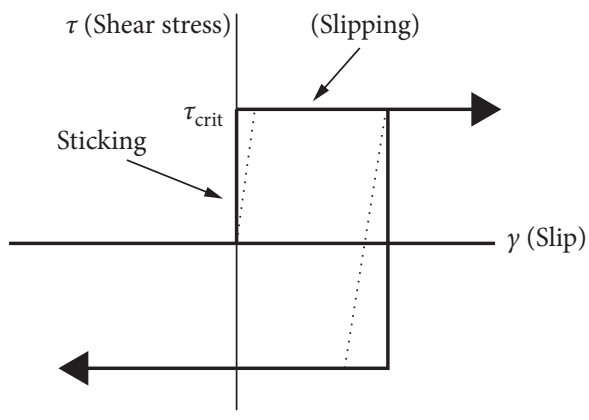

Figure 4: The frictional behavior of contact surfaces.

achievable. Hence, some terms must be considered that by a partial model of the infinite environment, the state of radiation (i.e., the waves are not reflected from the infinite environment) is satisfied. If the force, displacement, and dynamic stiffness upon the infinite boundary are displayed with $P(x, t)$ and $U(x, t) K(x, t)$, respectively, the following equation is settled:

$$
K(x, t)=\frac{P(x, t)}{U(x, t)} .
$$

The purpose of the study soil and structural interaction is to obtain the dynamic stiffness and shape of the wave motion in the meeting points of soil and structure. The direct solution method for studying soil and structure interaction is based on the formulation of finite elements for soil and structure. This feature emphasizes the importance of the method in the topic of the interaction of soil and structure. Another significant point is the ability of the finite element method to consider nonlinear effects, both material and geometric. This makes the method one of the most potent numerical methods in structural analysis.

2.6. Loading Surface Blast. When an explosion occurs under ideal conditions of the theory, in the vicinity of the solid surface, waved shape will be hemispherical (Figure 5). (It should be noted that during an explosion within the air, the wave front is spherical.) Therefore, the energy of the blast wave is concentrated into a smaller area. For this purpose, all the relations obtained for blasting in the air can be utilized by doubling the weight of the explosives. However, in cases where the ground surface is firm and impermeable, laboratory tests are recommended.

The parameters of the blast wavefront are significant. The analytical solution of these parameters was first expressed by Huganiot and Rankine to describe shocks in the ideal gas. These equations are expressed for the velocity of the wavefront $U_{s}$ and maximum dynamic compression $q_{s}$ as follows [10]: $p_{s} p_{0}$, and $a_{0}$ are the static overcompression, atmospheric compression, and velocity of sound, respectively, within the air under atmospheric compression. The scaling distance, $Z$, is defined as follows: [R3] is the actual distance from the center of the explosive to the target point, and $\mathrm{W}$ is the charge mass in kilograms of TNT. Utilizing $Z$ allows us to have a concise and practical expression of the blast wave for various situations [10]: 


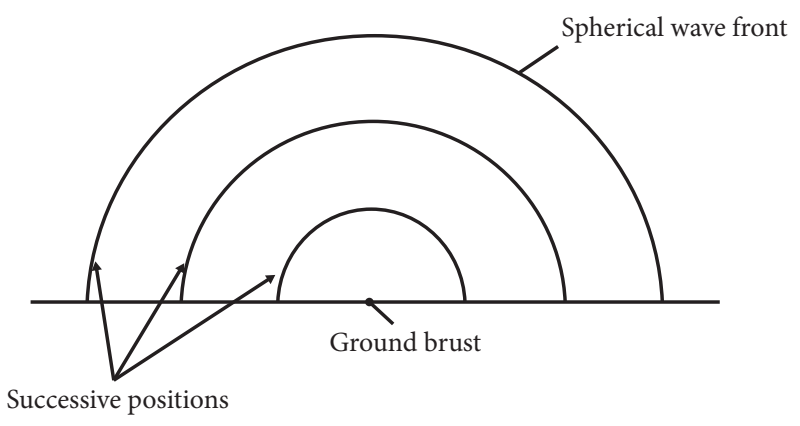

Figure 5: The hemispherical wave in superficial explosion.

$$
\begin{aligned}
U_{s} & =\sqrt{\frac{6 p_{s}+7 p_{0}}{7 p_{0}}} \cdot a_{0}, \\
q_{s} & =\frac{5 p_{s}^{2}}{2\left(p_{s}+7 p_{0}\right)}, \\
Z & =\left(\frac{R}{W^{(1 / 3)}}\right) .
\end{aligned}
$$

An equivalent TNT mass is required before the parameters can be extracted for an explosion. There are several ways to express equivalent TNT, but the simplest is the ratio of the specific mass energy of actual explosives to the specific mass energy of TNT. The specific gravity energy of TNT is equal to $6700 \mathrm{~kJ} / \mathrm{kg}$ [11]. Other parameters of the blast wave include the positive phase duration $T_{s}$ and the positive impulse $i_{s}$, which is the area under the compression-time diagram from time $t_{a}$ to the end of the positive phase [11]. A standard method for extracting blast wave parameters is to practice graphs provided in some sources, such as TM5-1300 [10]:

$$
\begin{aligned}
i_{s} & =\int_{t_{a}}^{t_{a}+T_{s}} p_{s}(t) \mathrm{d} t, \\
i_{s}^{+} & =\int_{t_{a}}^{t_{a}+t_{0}^{+}}\left[P(t)-P_{a}\right] \mathrm{d} t, \\
i_{s}^{-} & =\int_{t_{a}+t_{0}^{+}}^{t_{a}+t_{0}^{+}+t_{0}^{-}}\left[P_{a}(t)-P(t)\right] \mathrm{d} t .
\end{aligned}
$$

There are many relations to maximum overcompression due to conventional (chemical) explosions based on researchers' explosive applied. Kiran's relation to the traditional chemical explosion is given [4]: maximum overcompression curves (as well as the curves of other parameters of the blast wave) exist as a function of the distance measured in 1300-500 related to the defense organization. And the maximum overcompression can be obtained by utilizing them (Figure 6):

$$
\frac{P_{S}^{+}}{P_{0}}=\frac{808\left[1+(Z / 4.5)^{2}\right]}{\left\{\left[1+(Z / 0.048)^{2}\right]\left[1+(Z / 0.32)^{2}\right]\left[1+(Z / 1.35)^{2}\right]\right\}^{0.5}} .
$$

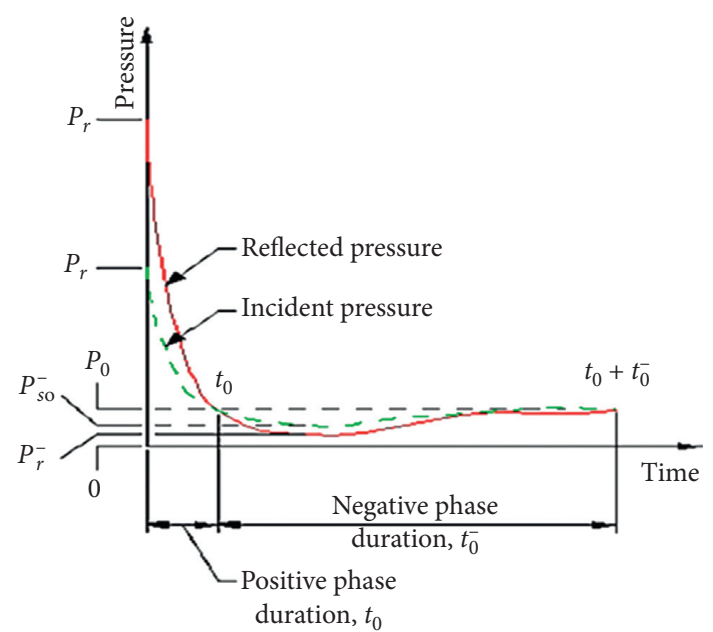

FIgURE 6: The ideal blast wave.

When an explosive device explodes on the surface of the earth or at a very short distance from it, the blast wave will ideally have a hemispherical wavefront, which is different from the spherical wavefront obtained in an aerial explosion [10]. Therefore, the released energy is applied to a smaller surface, and corrective coefficients must be applied to the air blast equations to obtain the overcompression in the surface explosion. Within 1963, Newmark proposed the following relation for calculating the maximum overcompression in chemical surface explosions:

$$
P_{s}=6784 \frac{W}{R^{3}}+93\left(\frac{W}{R}\right)^{0.5} \text { (bars), }
$$

where $P_{s}$ is the overcompression, $W$ is the equivalent weight of TNT (tons), and $R$ is the distance from the center of the explosion on the ground to the desired point in terms of meters (Figure 7).

In studies conducted by various researchers such as Bulson, Bashara, and Henrich on the case of blasts, experiments were reported based on the amount of explosive equivalent TNT; therefore, it seems essential to provide a correlation to equate other explosives with TNT. The mass of explosives can be converted to TNT using the combustion temperature [12]:

$$
\begin{aligned}
w_{\mathrm{TNT}} & =\frac{H_{\mathrm{EXP}}}{H_{\mathrm{TNT}}} w_{\mathrm{EXP}},(\text { chemical explosion }) . \\
w_{\mathrm{TNT}} & =k_{j} W_{j}, \\
k_{j} & =\frac{0.5}{0.7}, \text { (nuclear explosion). }
\end{aligned}
$$

In these relations, $w_{\mathrm{TNT}}, H_{\mathrm{TNT}}, H_{\mathrm{EXP}}, w_{\mathrm{EXP}}$, and $W_{j}$ are equivalent to TNT weight, TNT combustion temperature, the explosive combustion temperature, the weight of the explosive, and the energy equivalent of a nuclear explosion (e.g., the amount of TNT $T$, which produces energy equivalent to the energy of a nuclear blast), respectively. Also, $K_{j}$ is a factor related to the amount of actual energy released as a blast wave (a blast wave of nuclear explosives 


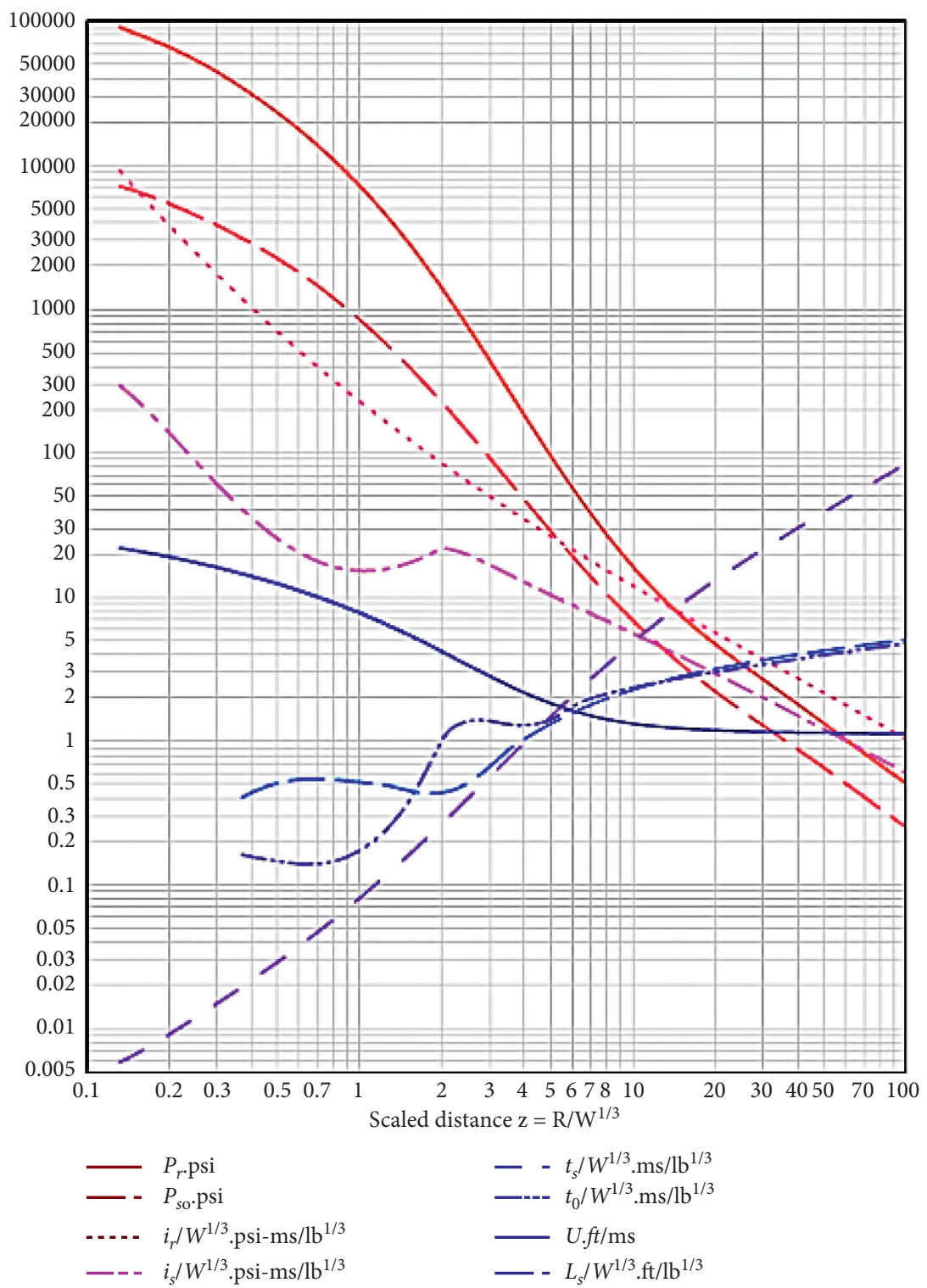

FIGURE 7: Spherical blast wave parameters, at sea level TM5-1300 (1969).

accounts for $70 \%$ of total energy, and the rest of it is wasted in the form of light and radiation) Table 2 [13].

2.7. Study of the Propagation of Blast Waves in the Soil Environment. The compressive waves created due to the explosion propagate in the soil environment, and colliding with the soil causes the soil to crumble and flow [14]. After the explosion, the resulting compressive wave propagates rapidly at a velocity close to sound velocity (about $300 \mathrm{~m} / \mathrm{s}$ ). This wave puts a compression of about 1000 pounds per square inch. Other letters are waves of tension or shock. The boundary impact between two different materials on how the wave propagates can be significant. Estimating the relative amplitude and directions in which the waves are reflected or refracted at the boundaries is available, utilizing the relations obtained from the theory of elasticity. Using the following equation also holding wave velocity and mass density, we can obtain the relation between $A_{i}$ and $A_{r}$ where $c, \rho$, and $A_{i}$ are the velocity of the wave, density, and the amplitude of the initial stress wave, respectively. Moreover, $A_{r}$ is the amplitudes of the reflected stress wave:

$$
\frac{A_{r}}{A_{i}}=\frac{\rho_{1} c_{1}-\rho_{2} c_{2}}{\rho_{1} c_{1}+\rho_{2} c_{2}} .
$$

The behavior of soil under dynamic loading is one of the most exciting topics for engineers in mines, buildings, and defense structures. Generally, the soil is a three-phase mixture of solid mineral particles, water, and the air. Connected or separated solid particles form the soil skeleton. Water and air are located among the cavities between solid particles of soil. Soil is the three-phase mixture; that is why it is challenging to predict the deformation of soils; not only is 
TABLE 2: Conversion coefficient for different explosives.

\begin{tabular}{lccccr}
\hline HBX2 & Minol 2 & Composition B & Amatol & TNT & Explosive material \\
\hline 1.30 & 1.34 & 1.04 & 1.04 & 1 & Conversion coefficient \\
\hline
\end{tabular}

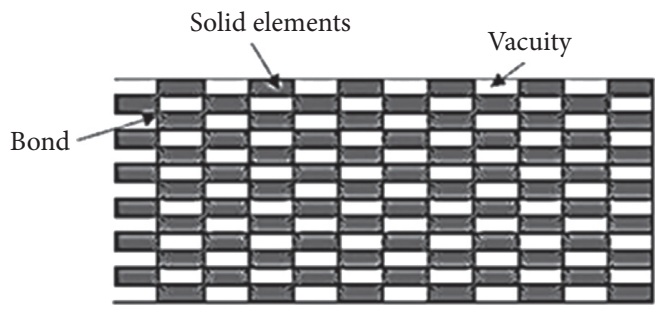

(a)

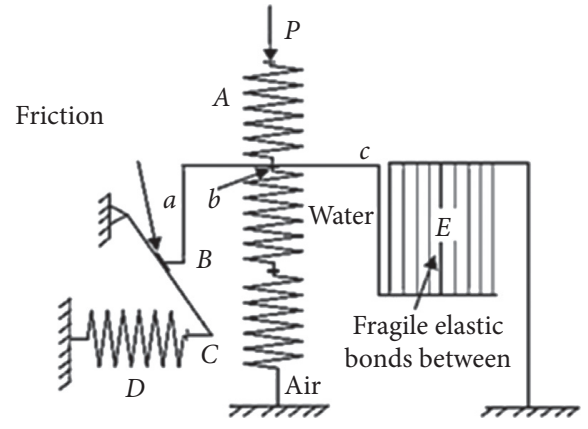

(b)

FiguRE 8: Wang three-phase behavior model for blast load: (a) conceptual model; (b) mathematical model.

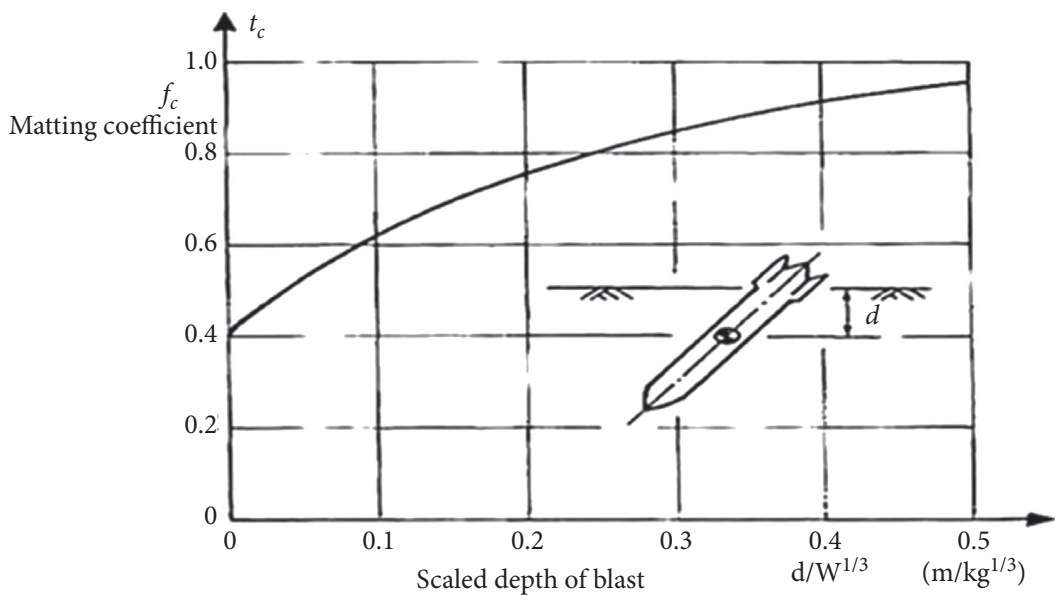

FIgUre 9: Mating coefficient.

the skeletal structure complex, but the properties of each component are fundamentally different. The different deformation characteristics of each phase and soil-structure make the soil deformation mechanism strongly dependent on the ratio of components in the soil and loading conditions. As a result, the mechanism of deformation of saturated and unsaturated soils is different, and such a difference in dynamic loading will be much more noticeable than static loading.

Both the mechanisms of skeletal deformation and the deformation of all soil phases affect simultaneously. However, in different loading stages and depending on the different ratios of components in the soil, one of the mechanisms is dominant so that the other mechanisms can be ignored [15]. For dry soils, which include a large amount of air and have a low percentage of water, the first mechanism prevails when subjected to static loading or slow dynamic loading. The initial compaction of the air is extreme. However, by increasing compression, the bonds between the soil particles are deformed; furthermore, the soil skeleton is damaged. Such soil is considered dense soil. Then, the second mechanism becomes more critical while the first mechanism gradually disappears [16].

The extraordinary dependence of soil properties on loading conditions makes it tough to develop a unique model for the deformation of soils under dynamic loading, particularly for high explosion rate loading, which varies significantly in different mass charge situations under loading conditions. Within an explosion, the soil close to the mass charge is deeply compacted. Hence, a high-stress wave is generated and propagates outward into the soil. As the distance from the charge increases, the stress wave decreases rapidly, and as a result, the soil compaction decreases. Therefore, in areas close to the charge, the second mechanism is predominant. In contrast, with increasing distance from the mass charge, the first mechanism becomes more and more significant and finally dominates the deformation of the soil. The extent of the nearby area depends on the 
TABle 3: The value of the reduction coefficient.

\begin{tabular}{lc}
\hline Reduction coefficient $(n)$ & Soil type \\
\hline 1.5 & Saturated clay \\
2.5 & Semisaturated clay and silt \\
2.5 & Very dense sand (dry or wet) \\
2.75 & Dense sand (dry or wet) \\
3 & Loose sand (dry or wet) \\
3.25 & Very loose sand (dry or wet) \\
\hline
\end{tabular}

fundamental characteristics of the soil. Soil deformation mechanisms under static and transient loading have been studied over the years, and many models have been proposed to describe soil behavior under such loads.

However, insufficient research studies have been conducted on soil behavior under transient loads, such as explosion loads, due to these complexities. Modeling the soil response to an extremely variable pressure requires a robust soil model because new behavioral models typically cover a small range of deformations. Besides, in such high-stress conditions, in the vicinity of the charge, it is illogical to consider the rigid materials for the soil particles considered in ordinary soil dynamics. Instead, the solid phase change should be regarded in the soil behavior model. Based on Kandaur's conceptual analysis of soil deformation, a threephase behavioral model for shock loading was developed by Wang (2003) to provide all of these requirements. In this model, the soil is considered a three-phase system consisting of solid particles, water, and air, in which the climate fills the solid particles form the soil skeleton, and the space between the particles is filled by water and air. The solid phase is considered plastic. Since the blast load duration is concise and there is not enough time for the water and air to escape from the soil particles, the relative displacement of the airwater and soil skeleton is neglected. Therefore, the model is suitable for describing soil behavior under normal blast loading [17].

In Figure 8, elements $A, B$, and $C$ represent the deformation of the solid particles, water, and air, respectively, and elements $D$ and $E$ expose the friction and adhesive strength between the solid particles. The bonds between solid particles have been represented by a series of strings. Elements $A, B$, and $C$ reflect the second deformation mechanism, and elements $D$ and $E$ are related to the first deformation mechanism. Based on the preceding modeling, a soil model for shock loading is obtained, which includes the following: equation of state (EOS), stress-strain relation, resistance model, and failure model for soil skeleton [18]. Different techniques are available in the technical literature to model a blast wave on buried structures. These impacts are in the form of displacement waves, acceleration, or compression. Naturally, the source of all methods is the same and is accomplished by solving the shock wave propagation equations in the soil environment. Of course, these relations are also interchangeable. The maximum amount of particle displacement $(x)$ in terms of meters, at a distance of $R$ (meters) from the source of the explosion, entirely or relatively buried, can be estimated from relation (22), where $w$ is the mass of the explosive material in kilograms, $c$ is the
TABLE 4: Models built to analyze the sensitivity of soil model dimensions.

\begin{tabular}{lccc}
\hline Height $(\mathrm{m})$ & Width $(\mathrm{m})$ & Length $(\mathrm{m})$ & Model no. \\
\hline 100 & 100 & 100 & 1 \\
50 & 100 & 100 & 2 \\
25 & 50 & 100 & 3 \\
15 & 25 & 50 & 4 \\
\hline
\end{tabular}

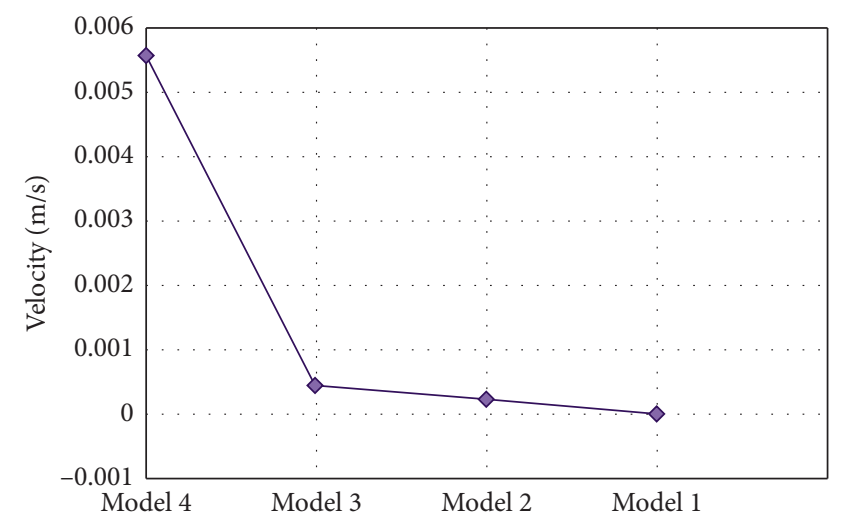

FIGURE 10: Graph of wave velocity values at the farthest nodes of different models.

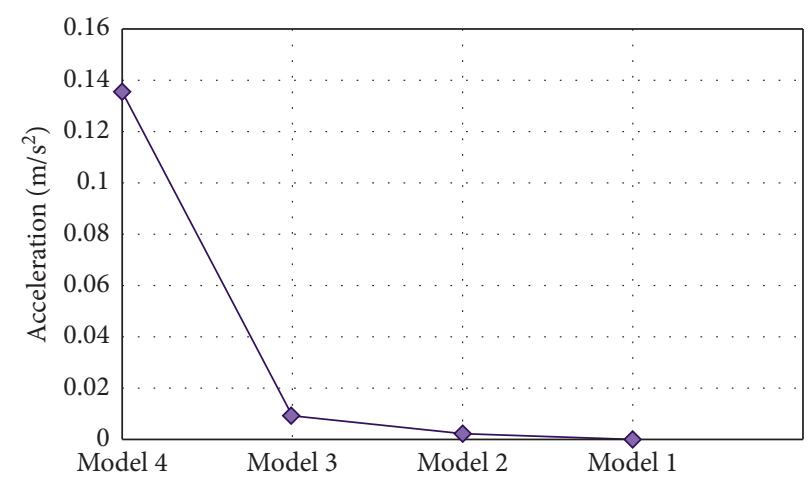

FIGURE 11: Graph of wave acceleration values at the farthest nodes of different models.

seismic wave velocity in meters per second, $f_{c}$ is the coupling coefficient, calculated from Figure 9 , and $n$ is the dimensionless reduction coefficient; from Table 3, it is obtained that [19]

$$
\frac{x}{w^{(1 / 3)}}=60 \times \frac{f_{c}}{c}\left(\frac{2.52 R}{w^{(1 / 3)}}\right)^{1-n} .
$$

Also, the maximum velocity of particles in meters per second at a distance of $R$ (meters) from the explosion source was calculated from equation (23). Moreover, the maximum pressure of the free field was determined based on equation (24). P is the density of the soil $\left(\mathrm{kg} / \mathrm{m}^{3}\right), \mathrm{C}$ is the load wave velocity $(\mathrm{m} / \mathrm{s})$, and $P_{-} 0$ is in pascals. The loading wave velocity $C$ depends on the velocity of the seismic wave and the maximum particle velocity. $C$ is high at short distances 
TABLE 5: Characteristics of soil types used in the analyzes.

\begin{tabular}{lcccccccccc}
\hline Soil type & $\gamma\left(\mathrm{kg} / \mathrm{m}^{3}\right)$ & $C(\mathrm{kPa})$ & $\phi$ & $E(\mathrm{MPa})$ & $v$ & $\alpha$ & $k$ & $\beta$ & $K$ \\
\hline Soft sand & 1600 & 0 & 35 & 7 & 0.4 & 0.27 & 0 & 54.81 & 0.8 \\
Hard sand & 2000 & 0 & 25 & 14 & 0.3 & 0.19 & 0 & 44.53 & 0.85 & 44.81 \\
Clay & 1800 & 20 & 0 & 4 & 0.3 & 0 & 23.09 & 0 & 1 \\
\hline
\end{tabular}

TABLE 6: Steel mechanical properties.

\begin{tabular}{lccccc}
\hline Tank material & $\gamma\left(\mathrm{kg} / \mathrm{m}^{3}\right)$ & $E(\mathrm{GPa})$ & $v$ & $F_{y}(\mathrm{MPa})$ & $F_{u}(\mathrm{MPa})$ \\
\hline Steel X65 & 7850 & 203 & 0.3 & 448 \\
\hline
\end{tabular}

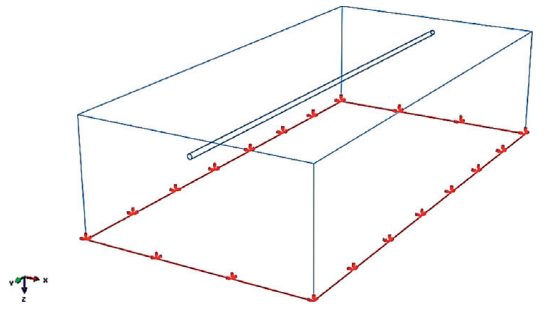

(a)

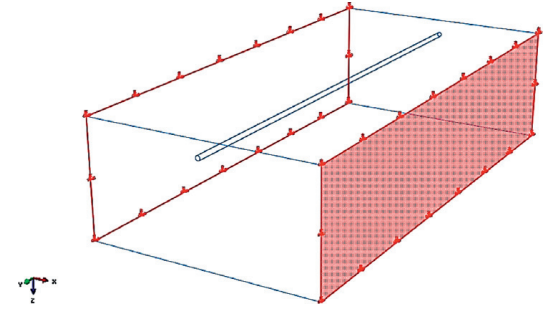

(b)



(c)

Figure 12: Conditions of symmetry at the lateral boundaries of the soil.

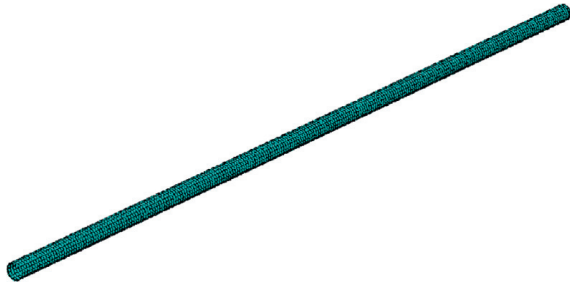

(a)

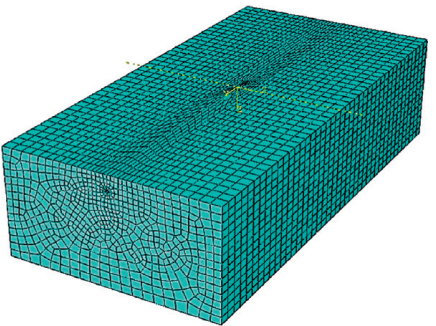

(b)

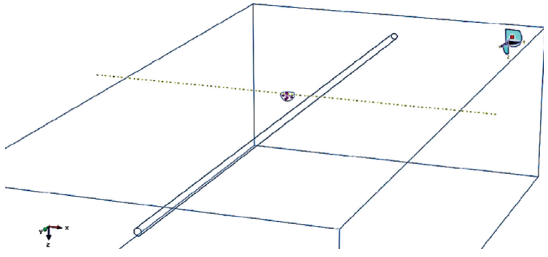

(c)

FIGURE 13: Place of blasting and meshing of soil and pipes.

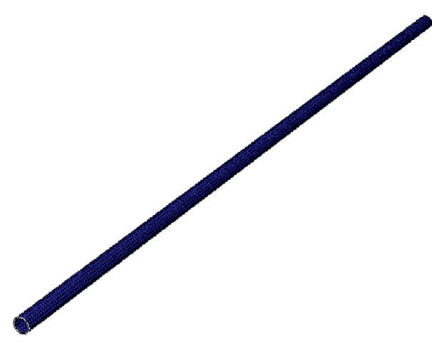

(a)

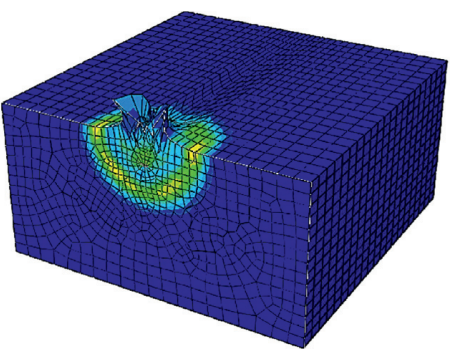

(b)

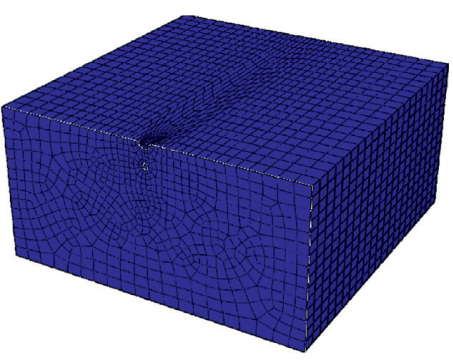

(c)

FIgURE 14: Continued. 


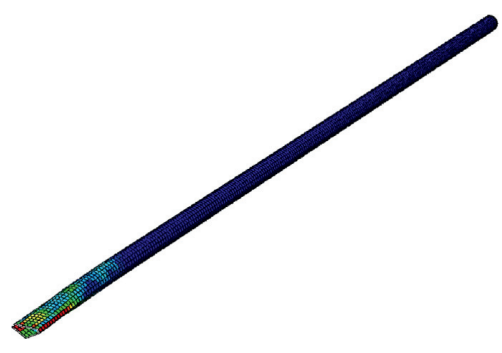

(d)

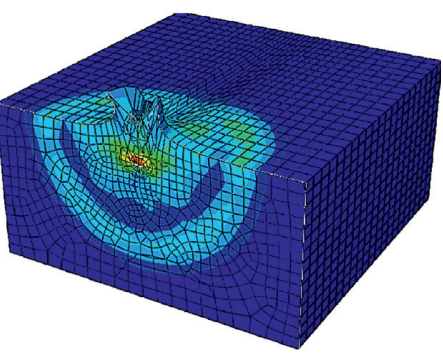

(e)

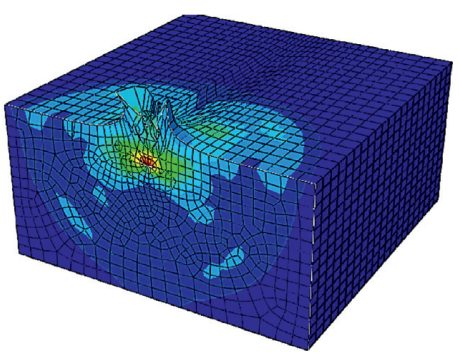

(f)

Figure 14: Propagation of the stress wave caused by the explosion in the soil and pipe environment.

TABLE 7: Specifications of models to investigate the effect of pipe burial depth.

\begin{tabular}{|c|c|c|c|c|c|c|c|}
\hline Case & Soil type & Diameter $(\mathrm{cm})$ & Thickness $(\mathrm{mm})$ & Pipe pressure (Psi) & Depth $(\mathrm{m})$ & $\mathrm{W}_{\text {TNT }}(\mathrm{kg})$ & Blast distance $(\mathrm{m})$ \\
\hline 1 & Clay & & & & 2 & & \\
\hline 2 & Hard sand & & & & 2 & & \\
\hline 3 & Soft sand & & & & 2 & & \\
\hline 4 & Clay & & & & 3 & & \\
\hline 5 & Hard sand & & & & 3 & 10 & \\
\hline 6 & Soft sand & & & & 3 & & \\
\hline 7 & Clay & & & & 4 & & \\
\hline 8 & Hard sand & & & & 4 & & \\
\hline 9 & Soft sand & & & & 4 & & \\
\hline 10 & Clay & & & & 2 & & \\
\hline 11 & Hard sand & & & & 2 & & \\
\hline 12 & Soft sand & & & & 2 & & \\
\hline 13 & Clay & & & & 3 & & \\
\hline 14 & Hard sand & 100 & 14.3 & $250(=1.732 \mathrm{MPa})$ & 3 & 20 & 0 \\
\hline 15 & Soft sand & & & & 3 & & \\
\hline 16 & Clay & & & & 4 & & \\
\hline 17 & Hard sand & & & & 4 & & \\
\hline 18 & Soft sand & & & & 4 & & \\
\hline 19 & Clay & & & & 2 & & \\
\hline 20 & Hard sand & & & & 2 & & \\
\hline 21 & Soft sand & & & & 2 & & \\
\hline 22 & Clay & & & & 3 & & \\
\hline 23 & Hard sand & & & & 3 & 30 & \\
\hline 24 & Soft sand & & & & 3 & & \\
\hline 25 & Clay & & & & 4 & & \\
\hline 26 & Hard sand & & & & 4 & & \\
\hline 27 & Soft sand & & & & 4 & & \\
\hline
\end{tabular}

due to the extraordinary velocity of the particles, but its value decreases as the seismic wave rises with increasing distance. Also, its quantity is never less than the seismic wave velocity [20]:

$$
u=48.8 \times f_{c}\left(\frac{2.52 R}{w^{(1 / 3)}}\right)^{-n}
$$

$P_{0}=\rho C u$,

$C=c$, (fully saturated clay soils),

$C=0.6 c+\left(\frac{n+1}{n-2}\right) u$, (saturated clay soils $)$,

$C=c+\left(\frac{n+1}{n-2}\right) u$, (sandy soils).
Also, the time of continuous explosion compression on underground structures is obtained from equation (26) in which $i_{0}$ is the specific momentum of the free zone, and placing the quantities of displacement and velocity of the particles in the above relation reaches the following relation for the time of total continuity equation (27). Inside the above relation, $t_{d}$ transpires in seconds, $R$ stands in meters, and $C$ is in meters per second. However, to make modeling the analysis more comfortable, the reflection pressure drop has been omitted. The relationship of the blast pressure on the pipe in time has become

$$
\begin{aligned}
& t_{d}=2 \frac{i_{0}}{P_{0}}, \\
& i_{0}=\rho C x,
\end{aligned}
$$




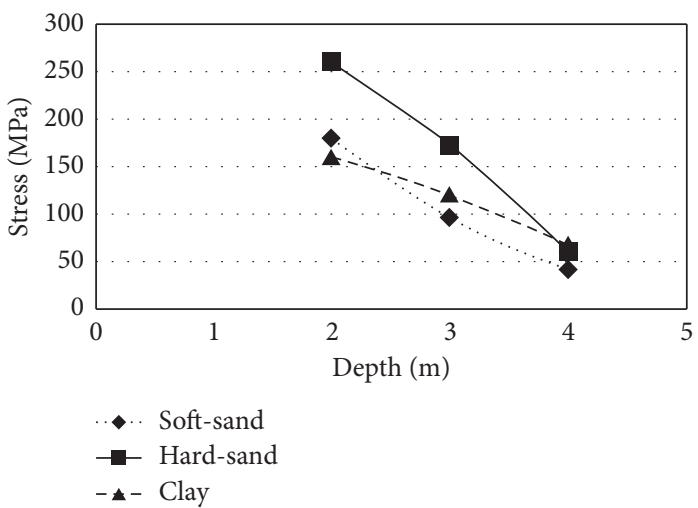

(a)

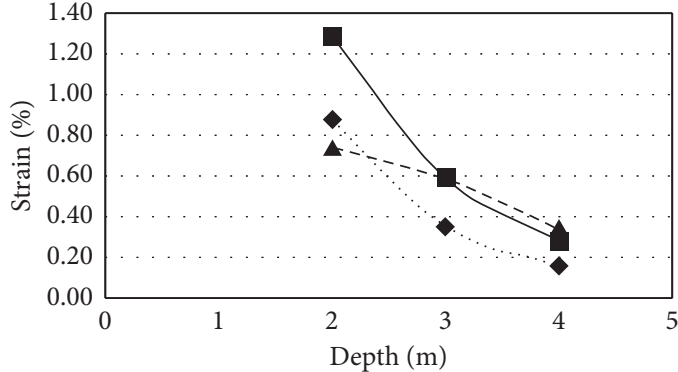

- . Soft-sand

$\rightarrow$ Hard-sand

- - Clay

(b)

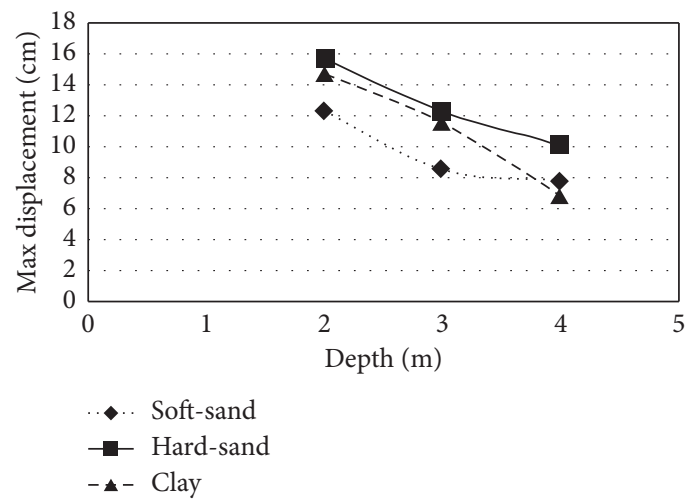

(c)

Figure 15: Analysis results to investigate the effect of pipe burial depth (explosion caused by $10 \mathrm{~kg}$ of TNT).

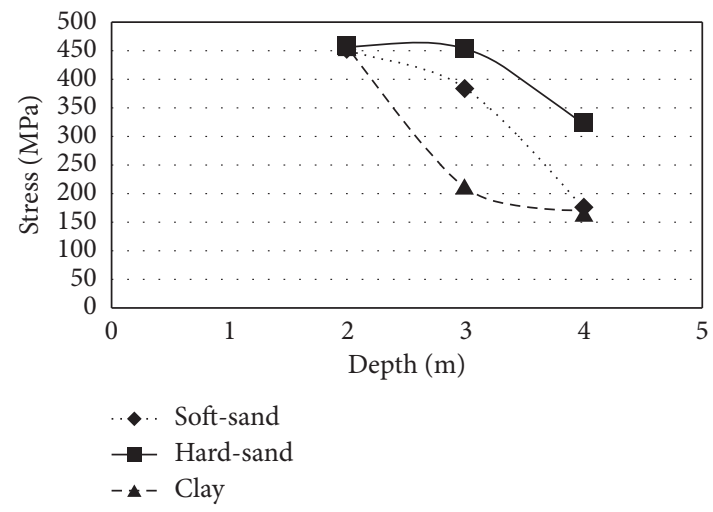

(a)

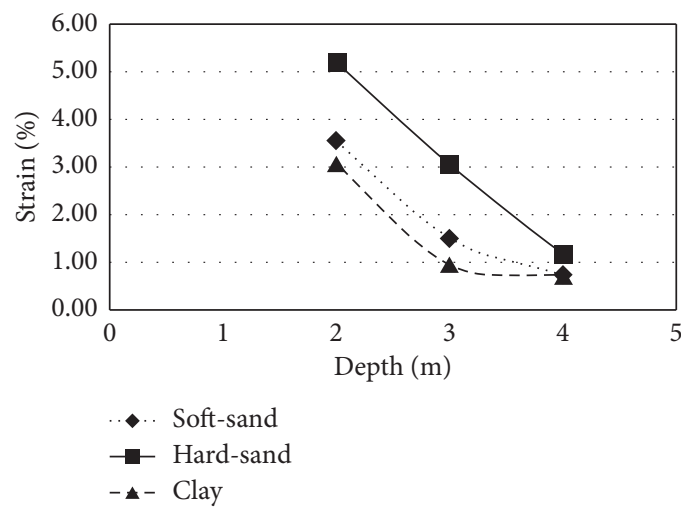

(b)

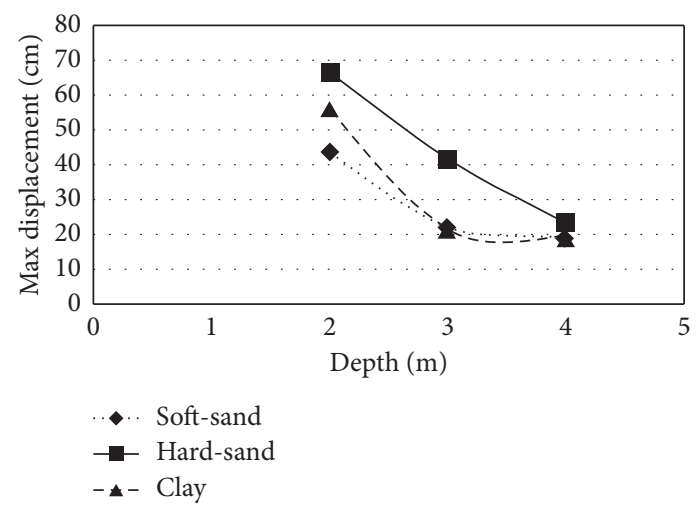

(c)

Figure 16: Analysis results to investigate the effect of pipe burial depth (explosion caused by $20 \mathrm{~kg}$ of TNT). 


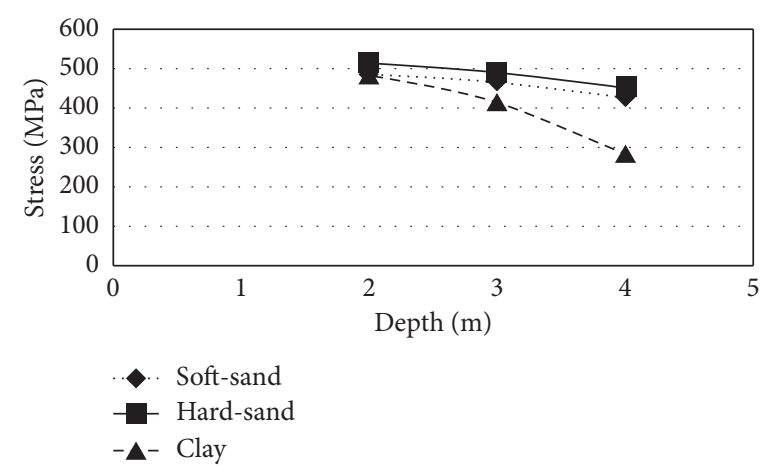

(a)

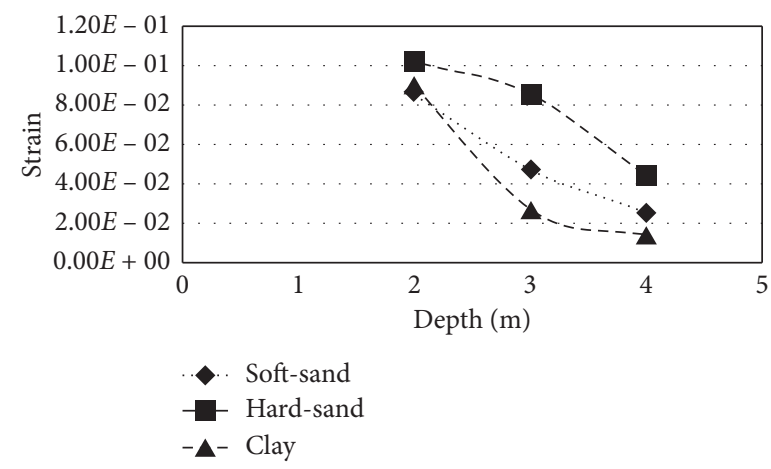

(b)

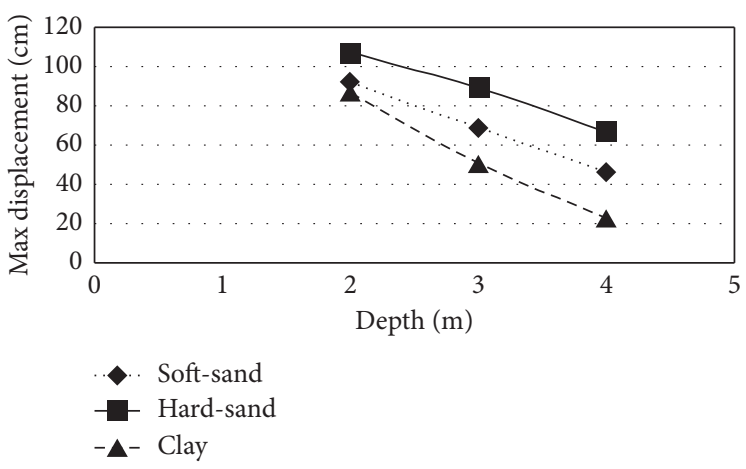

(c)

FIGURE 17: Analysis results to investigate the effect of pipe burial depth (explosion caused by $30 \mathrm{~kg}$ of TNT).

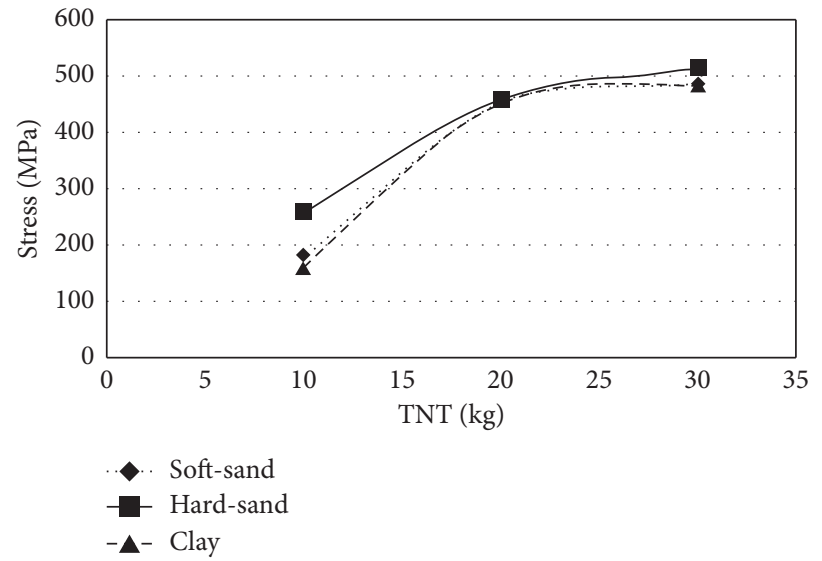

(a)

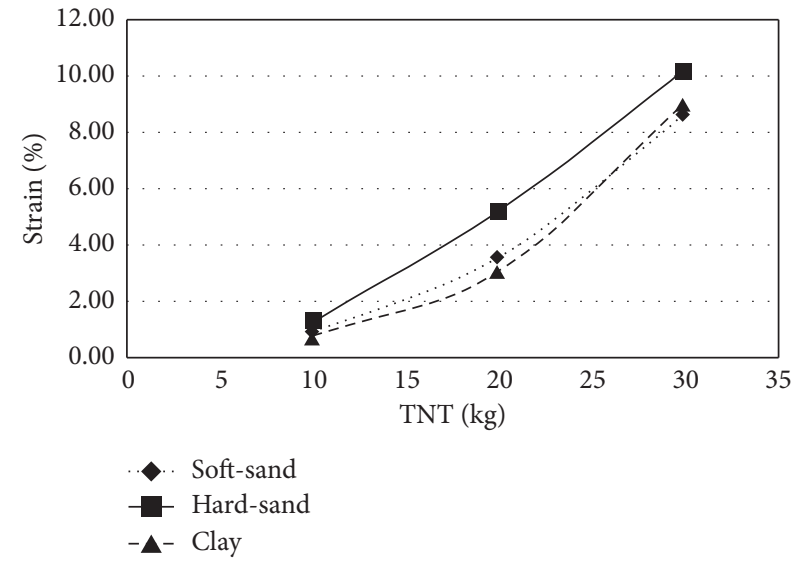

(b)

Figure 18: Continued. 


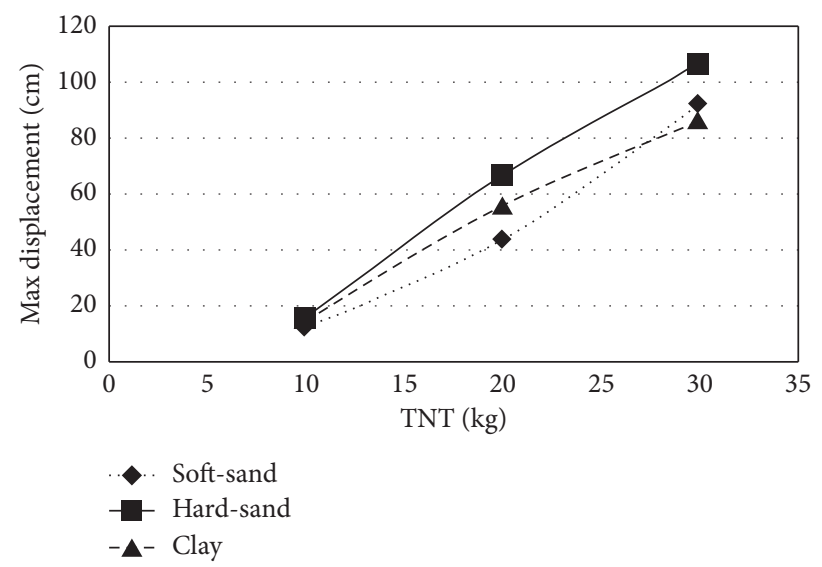

(c)

FIgURE 18: Analysis results to investigate the effect of explosive weight (pipe burial depth 2 meters).

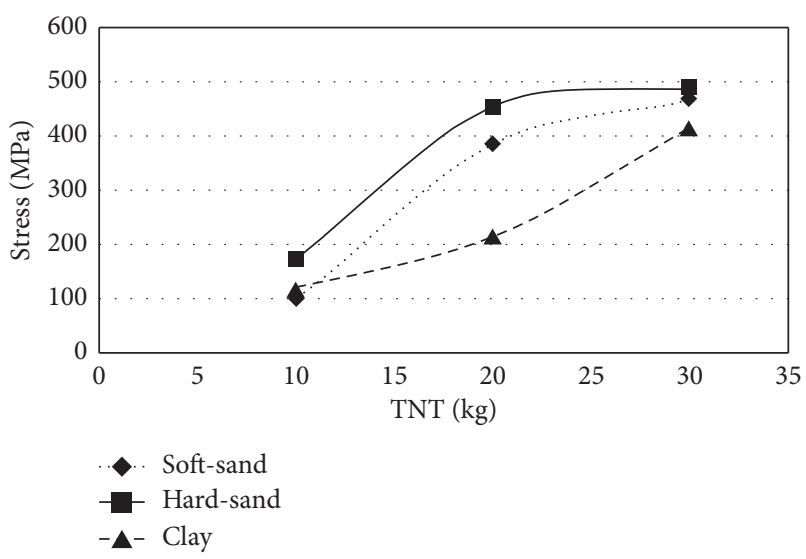

(a)

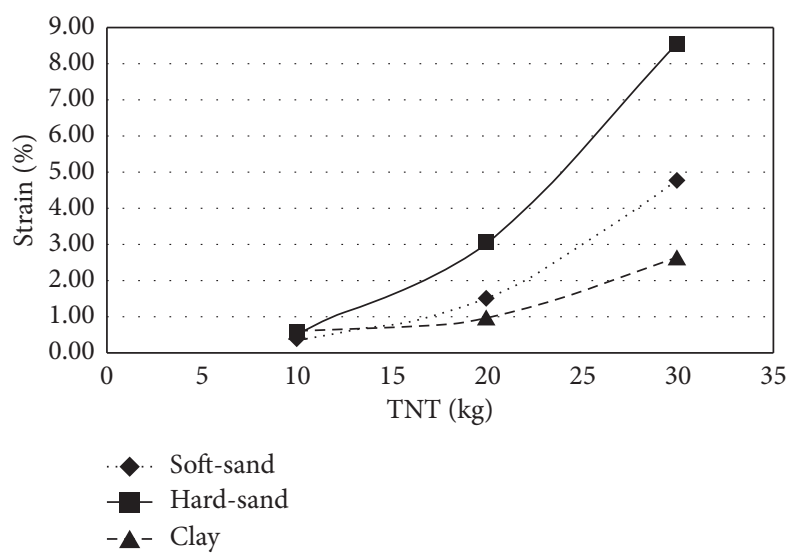

(b)

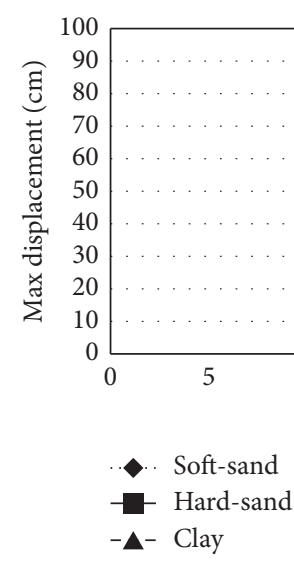

(c)

Figure 19: Analysis results to investigate the effect of explosive weight (pipe burial depth $3 \mathrm{~m}$ ). 


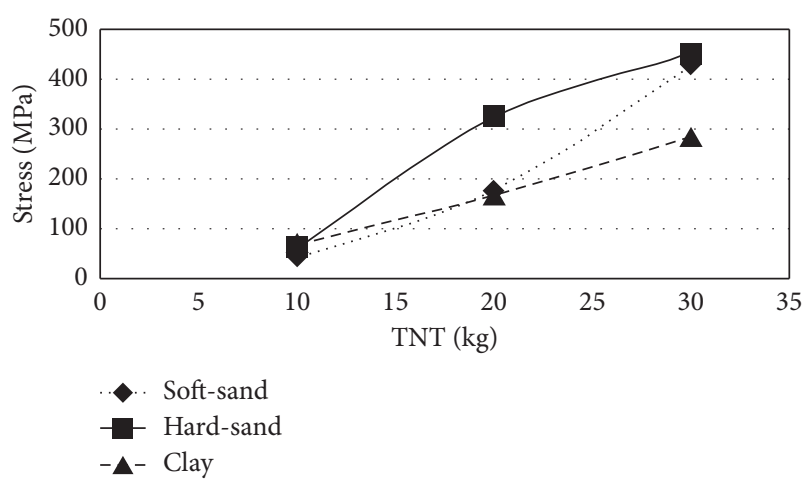

(a)

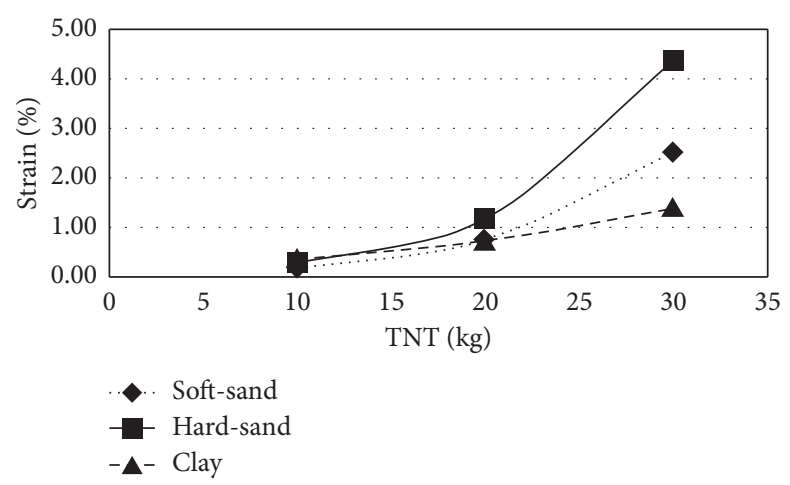

(b)
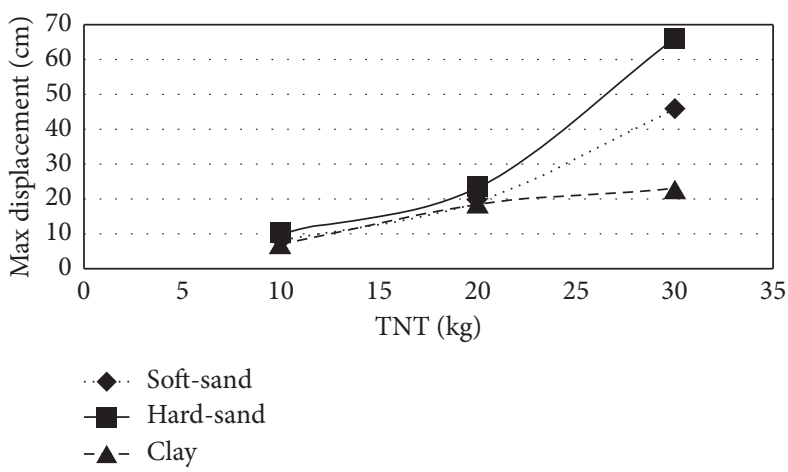

(c)

Figure 20: Analysis results to investigate the effect of explosive weight (pipe burial depth $4 \mathrm{~m}$ ).

TABLE 8: Specifications of models to investigate the effect of explosive weight.

\begin{tabular}{|c|c|c|c|c|c|c|c|}
\hline Case & Soil type & Diameter $(\mathrm{cm})$ & Thickness (mm) & Pipe pressure (Psi) & Depth $(\mathrm{m})$ & $\mathrm{W}_{\mathrm{TNT}}(\mathrm{kg})$ & Blast distance $(\mathrm{m})$ \\
\hline 1 & Clay & & & & & 10 & \\
\hline 2 & Hard sand & & & & & 10 & \\
\hline 3 & Soft sand & & & & & 10 & \\
\hline 4 & Clay & & & & & 20 & \\
\hline 5 & Hard sand & & & & 2 & 20 & \\
\hline 6 & Soft sand & & & & & 20 & \\
\hline 7 & Clay & & & & & 30 & \\
\hline 8 & Hard sand & & & & & 30 & \\
\hline 9 & Soft sand & & & & & 30 & \\
\hline 10 & Clay & & & & & 10 & \\
\hline 11 & Hard sand & & & & & 10 & \\
\hline 12 & Soft sand & & & & & 10 & \\
\hline 13 & Clay & & & & & 20 & \\
\hline 14 & Hard sand & 100 & 14.3 & $250(=1.732 \mathrm{MPa})$ & 3 & 20 & 0 \\
\hline 15 & Soft sand & & & & & 20 & \\
\hline 16 & Clay & & & & & 30 & \\
\hline 17 & Hard sand & & & & & 30 & \\
\hline 18 & Soft sand & & & & & 30 & \\
\hline 19 & Clay & & & & & 10 & \\
\hline 20 & Hard sand & & & & & 10 & \\
\hline 21 & Soft sand & & & & & 10 & \\
\hline 22 & Clay & & & & & 20 & \\
\hline 23 & Hard sand & & & & 4 & 20 & \\
\hline 24 & Soft sand & & & & & 20 & \\
\hline 25 & Clay & & & & & 30 & \\
\hline 26 & Hard sand & & & & & 30 & \\
\hline 27 & Soft sand & & & & & 30 & \\
\hline
\end{tabular}




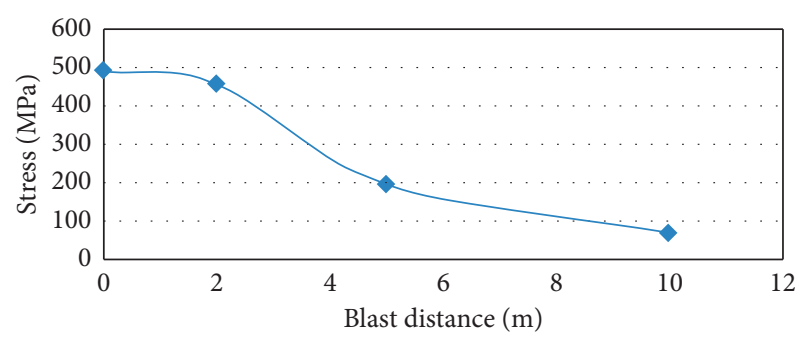

(a)

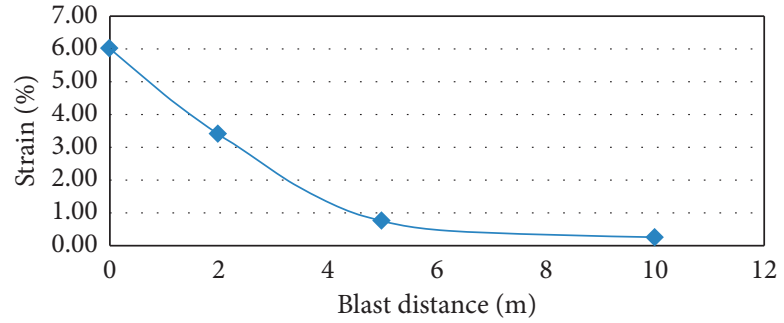

(b)

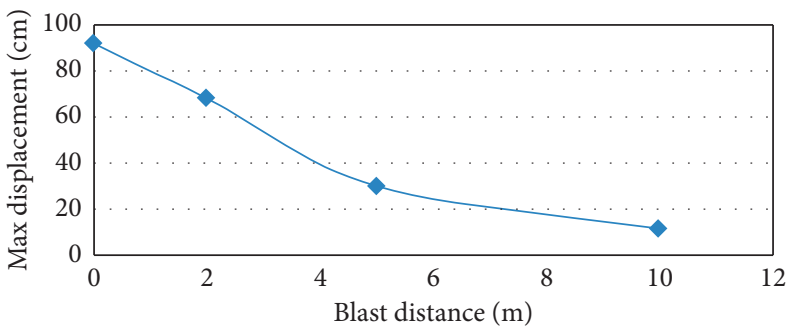

(c)

FIGURE 21: Analysis results to investigate the effect of blast distance from the pipe axis.

TABle 9: Specifications of models to investigate the effect of explosion distance from the pipe axis.

\begin{tabular}{|c|c|c|c|c|c|c|c|}
\hline Case & Soil type & Diameter $(\mathrm{cm})$ & Thickness $(\mathrm{mm})$ & Pipe pressure (Psi) & Depth $(\mathrm{m})$ & $\mathrm{W}_{\text {TNT }}(\mathrm{kg})$ & Blast distance $(\mathrm{m})$ \\
\hline 1 & & & & & & & 0 \\
\hline 2 & Soft sand & 100 & 14.3 & $250(=1.732 \mathrm{MPa})$ & 3 & 20 & 2 \\
\hline 3 & & & & & & & 5 \\
\hline 4 & & & & & & & 10 \\
\hline
\end{tabular}

TABLE 10: Specifications of models to investigate the effect of internal pipe pressure.

\begin{tabular}{|c|c|c|c|c|c|c|c|}
\hline Case & Soil type & Diameter $(\mathrm{cm})$ & Thickness $(\mathrm{mm})$ & Pipe pressure (MPa) & Depth $(\mathrm{m})$ & $\mathrm{W}_{\mathrm{TNT}}(\mathrm{kg})$ & Blast distance $(\mathrm{m})$ \\
\hline 1 & & & & 0 & & & \\
\hline $\begin{array}{l}2 \\
3\end{array}$ & Soft sand & 100 & 14.3 & $\begin{array}{c}1.732_{(=250 \mathrm{Psi})} \\
5\end{array}$ & 3 & 20 & 0 \\
\hline 4 & & & & 10 & & & \\
\hline
\end{tabular}

TABLE 11: Analysis results to investigate the effect of internal pipe pressure.

\begin{tabular}{lcc}
\hline Pipe pressure & Max displacement $(\mathrm{cm})$ & Stress $(\mathrm{MPa})$ \\
\hline No pressure & 43.7 & 452 \\
$250 \mathrm{psi}(=1.732 \mathrm{MPa})$ & 43.7 & 452 \\
$5 \mathrm{MPa}$ & 43.6 & 452 \\
$10 \mathrm{MPa}$ & 43.6 & 452 \\
\hline
\end{tabular}

TABLE 12: Specifications of models to investigate the effect of coefficient of friction between soil and pipe.

\begin{tabular}{|c|c|c|c|c|c|c|c|}
\hline Case & Soil type & Diameter $(\mathrm{cm})$ & Thickness $(\mathrm{mm})$ & Pipe pressure (Psi) & Depth (m) & $\mathrm{W}_{\text {TNT }}(\mathrm{kg})$ & Friction coefficient \\
\hline 1 & & & & & & & 0.4 \\
\hline 2 & & & & & & & 0.45 \\
\hline 3 & Soft sand & 100 & 14.3 & $250(=1.732 \mathrm{MPa})$ & 3 & 20 & 0.5 \\
\hline 4 & & & & & & & 0.55 \\
\hline 5 & & & & & & & 0.6 \\
\hline
\end{tabular}


TABLE 13: Analysis results to investigate the effect of coefficient of friction between soil and pipe.

\begin{tabular}{lccc}
\hline Friction coefficient & Max displacement $(\mathrm{cm})$ & Logarithmic strain & Stress $(\mathrm{MPa})$ \\
\hline 0.4 & 22.19 & $\% 1.50$ & 386 \\
0.45 & 22.20 & $\% 1.50$ & 391 \\
0.5 & 22.22 & $\% 1.51$ & 385 \\
0.55 & 22.26 & $\% 1.51$ & 386 \\
0.6 & 22.30 & $\% 1.50$ & 388 \\
\hline
\end{tabular}

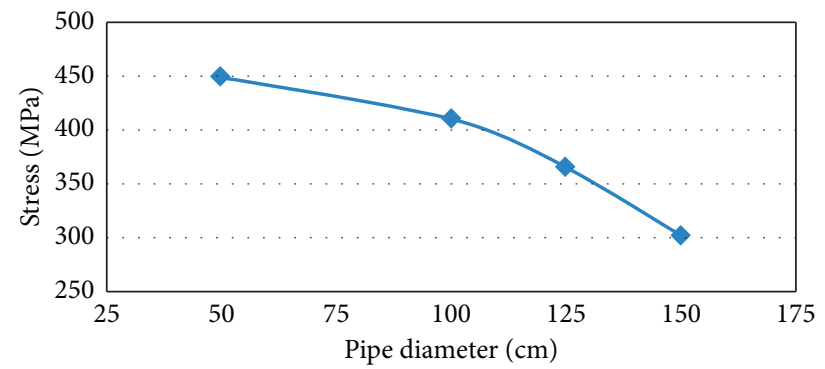

(a)

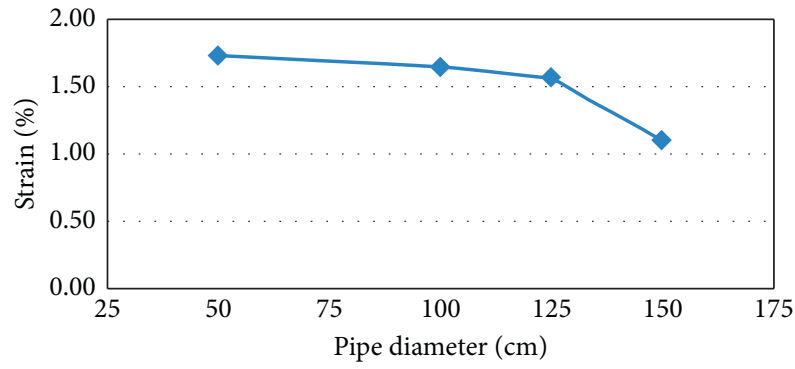

(b)

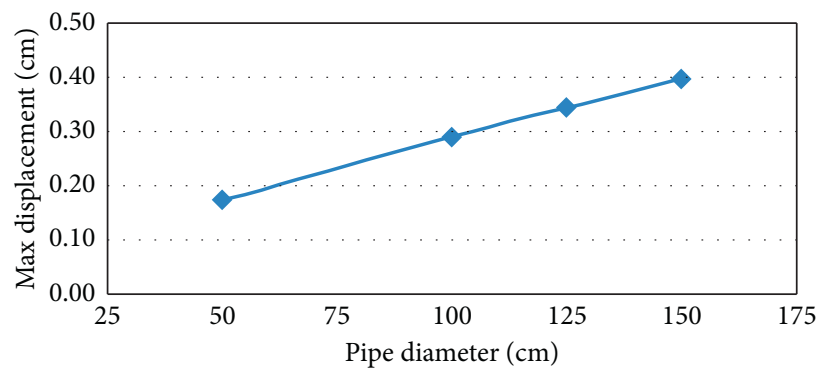

(c)

FIgURE 22: Analysis results to investigate the effect of pipe diameter.

TABLE 14: Specifications of models to investigate the effect of pipe diameter.

\begin{tabular}{|c|c|c|c|c|c|c|c|}
\hline Case & Soil type & Diameter $(\mathrm{cm})$ & Thickness (mm) & Pipe pressure (MPa) & Depth $(\mathrm{m})$ & $\mathrm{W}_{\mathrm{TNT}}(\mathrm{kg})$ & Blast distance $(\mathrm{m})$ \\
\hline 1 & & 50 & & & & & \\
\hline 2 & Soft sand & 100 & 14.3 & 1.732 (=250 Psi) & 3 & 20 & 0 \\
\hline $\begin{array}{l}3 \\
4\end{array}$ & sort sand & $\begin{array}{l}125 \\
150\end{array}$ & 14.3 & $1.132(=250 \mathrm{PS})$ & 3 & & \\
\hline
\end{tabular}

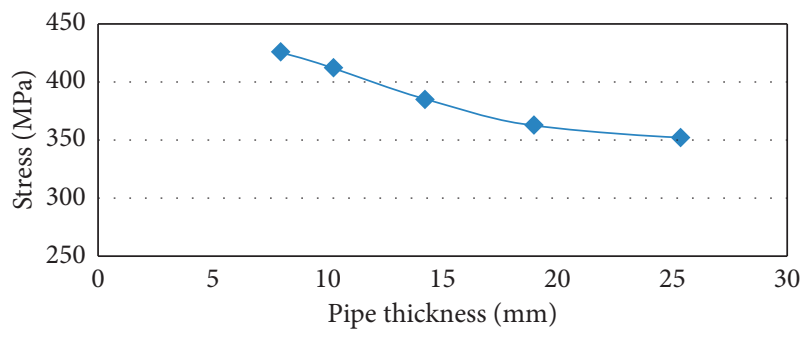

(a)

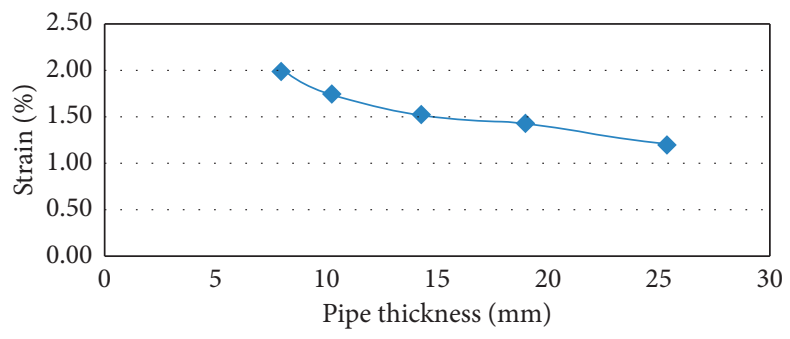

(b)

FIgURE 23: Continued. 


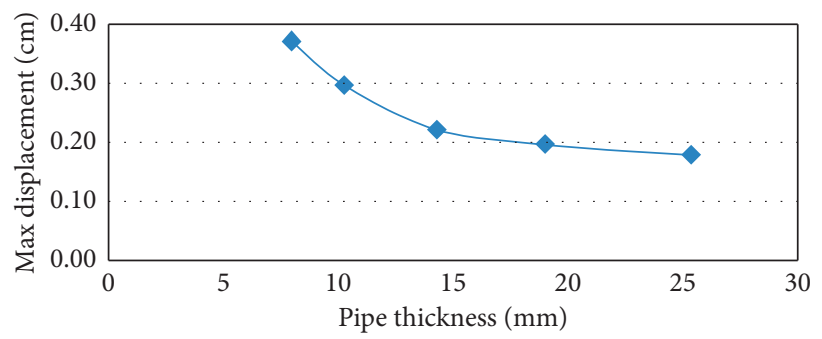

(c)

FIgURE 23: Analysis results to investigate the effect of pipe thickness.

TABLE 15: Specifications of models to investigate the effect of pipe thickness.

\begin{tabular}{|c|c|c|c|c|c|c|c|}
\hline Case & Soil type & Diameter $(\mathrm{cm})$ & Thickness $(\mathrm{mm})$ & Pipe pressure (Psi) & Depth (m) & $\mathrm{W}_{\mathrm{TNT}}(\mathrm{kg})$ & Blast distance $(\mathrm{m})$ \\
\hline 1 & & & 8 & & & & \\
\hline 2 & & & 10.3 & & & & \\
\hline 3 & Soft sand & 100 & 14.3 & $250(=1.732 \mathrm{MPa})$ & 3 & 20 & 0 \\
\hline 4 & & & 19 & & & & \\
\hline 5 & & & 25.4 & & & & \\
\hline
\end{tabular}

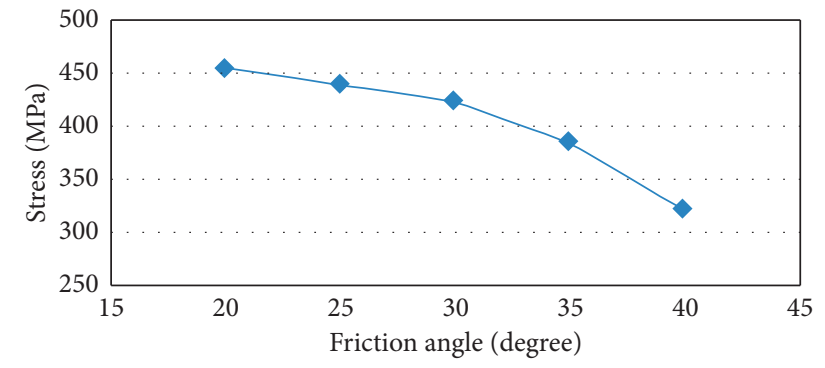

(a)

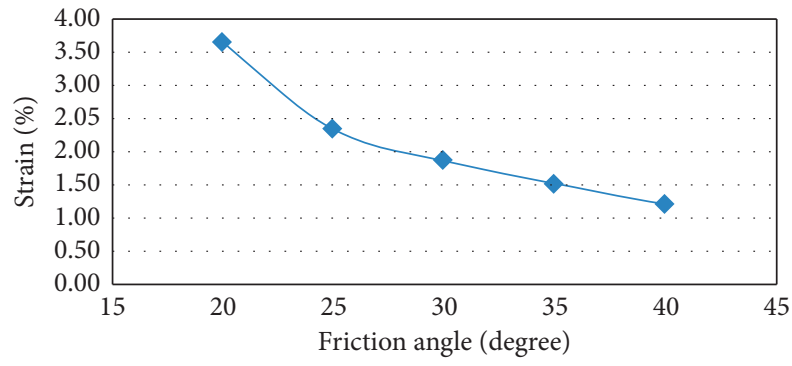

(b)

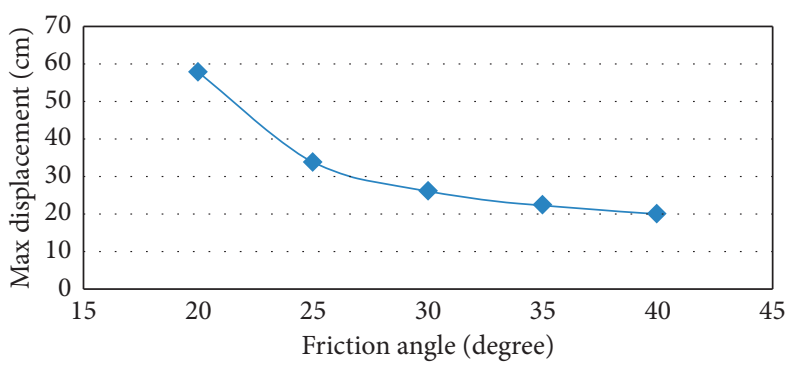

(c)

FIGURE 24: Analysis results to investigate the effect of internal soil friction coefficient.

TABLE 16: Specifications of models to investigate the effect of internal soil friction coefficient.

\begin{tabular}{|c|c|c|c|c|c|c|c|}
\hline Case & Soil type & Diameter $(\mathrm{cm})$ & Thickness (mm) & Pipe pressure (Psi) & Depth $(\mathrm{m})$ & $\mathrm{W}_{\mathrm{TNT}}(\mathrm{kg})$ & Friction angle \\
\hline 1 & & & & & & & 20 \\
\hline 2 & & & & & & & 25 \\
\hline 3 & Soft sand & 100 & 14.3 & $250(=1.732 \mathrm{MPa})$ & 3 & 20 & 30 \\
\hline 4 & & & & & & & 35 \\
\hline 5 & & & & & & & 40 \\
\hline
\end{tabular}




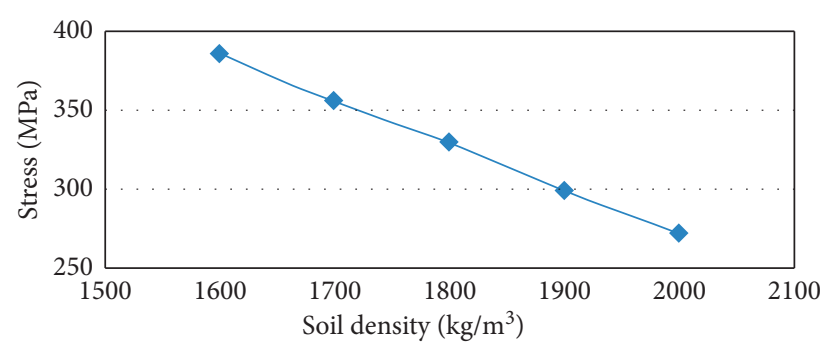

(a)

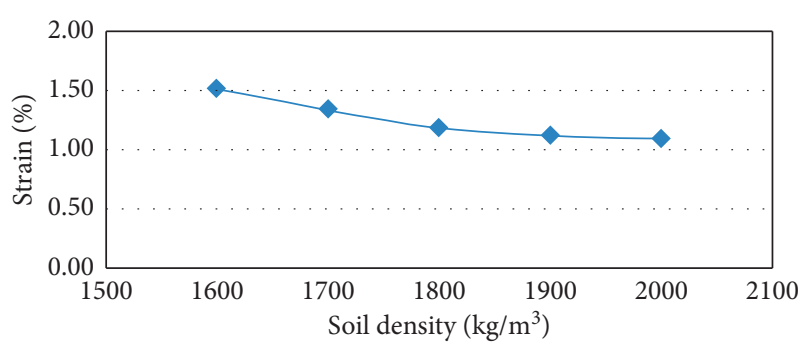

(b)

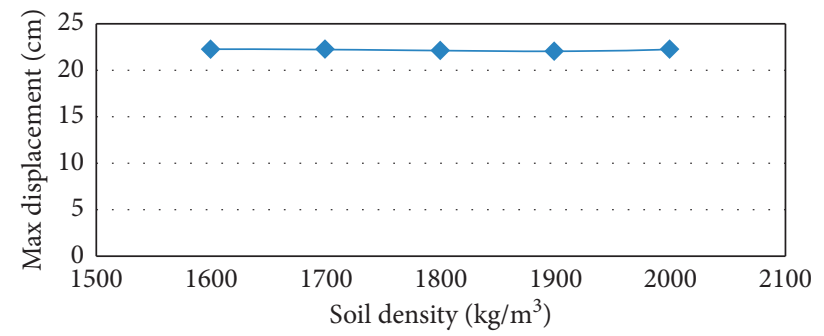

(c)

FIGURE 25: Analysis results to investigate the effect of soil specific gravity.

TABLE 17: Specifications of models to investigate the effect of soil specific gravity.

\begin{tabular}{|c|c|c|c|c|c|c|c|}
\hline Case & Soil type & Diameter $(\mathrm{cm})$ & Thickness (mm) & Pipe pressure (Psi) & Depth $(\mathrm{m})$ & $\mathrm{W}_{\mathrm{TNT}}(\mathrm{kg})$ & Soil density $\left(\mathrm{kg} / \mathrm{m}^{3}\right)$ \\
\hline 1 & & & & & & & 1600 \\
\hline 2 & & & & & & & 1700 \\
\hline 3 & Soft sand & 100 & 14.3 & $250(=1.732 \mathrm{MPa})$ & 3 & 20 & 1800 \\
\hline 4 & & & & & & & 1900 \\
\hline 5 & & & & & & & 2000 \\
\hline
\end{tabular}

$$
\begin{gathered}
t_{d}=6.1967 \frac{R}{C}, \\
P(t)=P_{r}\left(1-\frac{t}{t_{d}}\right) .
\end{gathered}
$$

\section{Modeling and Conclusion}

3.1. Sensitivity Analysis to Control Model Dimensions. Since the infinite soil environment is modeled in a finite form, the question arises about the dimensions of the soil model. Soil model dimensions should be chosen so that, while small, it has the least impact on the results; to minimize the time of analysis to get accurate results. Because the larger the model, the more accurate the results, but due to the larger dimensions of the model, the time of analysis is extended once the analysis of the model may take days. For this purpose, three models were made according to Table 4.

The above diagrams show the acceleration and wave velocity at the farthest node of the defined models (corner points) for the same loading and boundary conditions. According to this, it can be concluded based on obtained results (i.e., soil with dimensions of $50100100 \times 25 \mathrm{~m}$ ). The velocity and acceleration of the blast wave resulting from the explosion reaching the farthest node tend to zero. As the dimensions grow, only the analysis time increases, but there is no change in the results and outputs. Thus, the model that was considered for this project, according to the sensitivity analysis, is model 3, i.e., soil with dimensions of $100 \times 50 \times 25$ meters, Figures 10 and 11 .

3.2. Finite Element Model. The geometry of the model consists of two parts, soil and pipe. The dimensions of each are as follows: soil in the form of a cube with dimensions of $100 \times 50 \times 25$ meters, and a steel pipe with a diameter of 1 meter, a length of 100 meters, and a thickness of $3 / 14 \mathrm{~mm}$. After determining the geometry of the model, the specifications of the materials used should be defined. Soil and steel specifications are shown in Tables 5 and 6, respectively. For steel materials, the yield stress is equal to $0.5 \%$ strain, and ultimate tensile strength is equal to a $19 \%$ strain. The Drucker-Prager plastic model was also used to define soil behavior. All members are homogeneous. For pipe modeling, shell elements have been used, and for soil modeling, solid elements have been used.

Two methods can be applied in modeling soil-structure interaction. One is soil replacement modeling with springs in three directions (two directions perpendicular to the pipe and one direction tangent to the pipe). Another way is to build a full model, including soil, pipes, and their interaction in three dimensions. In this study, due to the closest 
approximation to reality, the second method was utilized. In this modeling, the interaction between soil and pipe elements within the software is modeled on surface-to-surface mode, between the outer surface of the pipe and the inner surface of the soil and by the penalty method. In this method, the normal contact of two levels with the hard contact method is considered to prevent the surfaces from sinking into each other. Also, the tangential interaction of the two surfaces with a friction coefficient of 0.5 that was suggested by Vasouras and Kolbadi $[21,22]$ is regarded in the analyzes. This number is a suitable value for the interaction of soil with metal structures. However, in a part of the study, the effect of the quantity of this coefficient of friction on the behavior of the pipe was investigated, and the results are presented below. Also, at this level, damping contact was considered with a coefficient of 0.05 .

Since the peripheral soil is semi-infinite, it must be modeled so that all its properties, including its being semiinfinity, are considered. Based on the previously performed sensitivity analysis (Figure 12), we saw that the velocity and acceleration of the blast wave that reaches the farthest node tend to zero $[23,24]$. When the wave reaches the farthest nodes from all sides, it is damped. Therefore, there is no need to use energy absorbing and damping boundaries on the edges of the soil environment. Thus, symmetry conditions can be utilized on the lateral surfaces of the soil model without any challenges [25]. Of course, it should be noted that these conditions, i.e., not using adsorbent and damping boundaries on the lateral surfaces of the soil environment, are appointed just because of the type of loading, i.e., explosion, as well as the dimensions considered for this model, and cannot be generalized to other situations [26]. For example, the conditions for earthquake loading are different. If the adsorbent and damping boundaries are not used on the lateral surfaces of the soil environment, the wave reflected from the structure by these boundaries is reflected in the environment and causes errors in the results [27]. Therefore, absorbing boundaries must be applied to prevent the reflection of the waves. The soil floor also has encastre boundary conditions.

3.3. Loading. The loads applied to the pipe include the load due to the blast wave, the internal pressure of the pipe, and the overburden soil weight of the pipe. The blast load is applied as a compression-time series for an equivalent TNT mass of 10, 20, and $30 \mathrm{~kg}$ at a point on the soil based on the equations presented equation (22). The place of the surface load application was a hole dug in the shape of a hemisphere with a radius of 1 meter on the soil surface. The internal pressure of the pipe was also applied as a uniform pressure on the inner surface of the pipe. Nine-node cubic elements were used in meshing the soil volume, which is smaller in sensitive areas in Figure 13.

3.4. Type of Analysis. Knowing the nature of each of these methods and gaining experience will be simple to choose the solution. In the explicit method, the results at each moment $\left(x_{n}+1\right)$ are obtained directly from the results before $\left(x_{n}\right)$. In this way, new situations are calculated by considering the velocity and acceleration of the elements at the moment $n$ and placing them in the following equation:

$$
x_{n+1}=x_{n}+\Delta t_{n+(1 / 2)} \dot{x}_{n+(1 / 2)} .
$$

On the other hand, in the implicit method, the size of $\Delta t$ does not matter much. In this method, the equations of position $\left(x_{n}\right)$, velocity $\left(x_{n}\right)$, and acceleration $\left(x_{n}\right)$ are solved simultaneously by iterative methods. In this way, there is no trace of speed and acceleration in the nodes. In high-speed physical phenomena, such as blast forces or collision forces that inflict a significant load on a structure in a short period, solver convergence is implicitly impossible. Besides, observation of the reaction of the structure in small time intervals is considered. The following is the process of spreading the stress wave propagation caused by the explosion in the soil and pipe under the blast load in Figure 14.

\section{Review of Analysis Results}

To analyze the sensitivity of the parameters affecting the performance of the pipe, the models and the results of their analysis are examined separately. The parameters that underlie the judgment are stress, strain, and displacement. The stress understudy is phonemic stress obtained from the square root of the sum of the principal stresses. Displacement also means the maximum absolute displacement of one of the pipe nodes.

4.1. The Impact of Pipe Burial Depth. Blast loading was performed on three types of soil (loose sand, hard sand, and clay) and its impact at three different depths. Depth of burial pipe tension, strain, and maximum displacement of the pipe is significantly reduced. The effect of increasing the burial depth of pipes on their behavior against explosion can be mentioned for various reasons, such as increasing the pipe blockage in the soil, increasing the distance of the pipe to the explosion place, and increasing the stiffness of the soil (Table 7). Therefore, it seems that the performance of buried pipes is better in clay soils and loose sands, respectively, especially with increasing pipe burial depth; this is evident. The phenomenon due to the higher seismic wave velocity in hard sandy soils is directly related to the modulus of elasticity of the soil and increases the blast wave maximum pressure (Figures 15-17).

4.2. The Impact of Explosive Weight. Based on the relations presented to calculate the mass charge, the weight of the mass charge directly affects the loads caused by the explosion. Therefore, according to the results obtained from the analysis of the models given in Figures 18-20, it can be stated that increasing the weight of charge mass, strain and maximum displacement of the pipe will increase. Here, too, the performance of pipes buried in loose soils and sands, particularly clay soils, seems to be better (Table 8 ).

4.3. The Impact of Blast Distance from the Pipe Axis. Based on the results obtained from the analysis of the models given in Figure 21, it can be said that by increasing the blast 
distance, strain and maximum displacement of the pipe will be significantly reduced. This decreasing trend tends to zero after specific distances (depending on the conditions), where it occurs after a distance of 5 meters (Table 9).

4.4. The Impact of Internal Pipe Pressure. According to the results of the analysis of the models, which are given in Table 10 and 11, it can be said that the internal pressure has little impact on the pipe response practically.

4.5. The Impact of Friction Coefficient between Soil and Pipe. According to the analysis results, which are given within Tables 12 and 13, it can be recognized that practically, the friction coefficient between the soil and the pipe has a negligible impact on the pipe response, due to the propagation of the wave, which is perpendicular to the axis of the pipe. Hence, the impact it has on the pipe is more inclined to normal type than the contact. So, the normal interaction of soil and pipes is much more critical than their contact interaction.

4.6. Pipe Diameter Impact. As expected, the larger the diameter of the pipe, the better the pipe performance as the cross-sectional moment of inertia increases based on Figure 22 and Table 14.

4.7. Pipe Thickness Impact. As expected, the thicker the pipe, the better the performance of the pipe as the moment of inertia increases as can be found in Figure 23 and Table 15.

4.8. The Impact of Soil Internal Friction Coefficient. Based on the results obtained from the analysis of the models given in Figure 24, it can be stated that by increasing the internal friction coefficient of the soil, the maximum strain and displacement of the pipe decrease (Table 16).

4.9. Soil Specific Gravity Impact. Based on the results of the analyzes given in Figure 25, it can be understood that by increasing the specific gravity of the soil, the maximum stress and strain of the pipe are significantly reduced (Table 17). However, there is no noticeable change in maximum pipe displacement.

\section{Conclusions}

Summary of the achievements of studying the performance of buried pipelines under the effect of explosive loading is presented in this section. Then, based on the author's experience, to reduce ambiguities, conduct experiments, furthermore analyze some of the obtained results, and also present a series of suggestions and approaches for using the results of this research, some ideas are mentioned in the suggestions section.

As can be seen, from the problem under study, first, a suitable model was constructed in three-dimensional form using the finite element method. Then, in the analysis, by changing the parameters that seemed to be important in the behavior of the pipe under the effect of the surface explosion, we examined the sensitivity of the pipe response to the change of the desired parameter. After analyzing and extracting the results, these results were presented in charts, which were based on judgments and conclusions about pipe behavior. At the end of the analysis used in this study, results were obtained to understand better the behavior and optimal design of buried pipelines under the impact of surface explosions, which are mentioned as follows:

(1) Blast wave arrival velocity depends on the velocity of the soil environment compressive seismic wave. The arrival time of the wave in clay soils is longer than other soils. The blast wave response time to the structure is a significant factor for the response of underground structures such as buried pipes.

(2) Due to the low mass of the pipe and the high dependence of its behavior on the strains that occur in the surrounding soil, it can be stated that the entering velocity spectrum of the pipe is much more critical than the acceleration spectrum.

(3) As the pipe depth increases, the maximum stress, strain, and displacement of the pipe decrease almost linearly. Buried pipes seem to perform better in clay soils and loose sands, respectively, especially while the burial depth of the pipe increases. The reason is that this phenomenon is the higher seismic wave velocity in stiff sandy soils, which is directly related to the modulus of soil elasticity and increases the maximum blast wave compression.

(4) By increasing the blast distance from the tension pipe axis, the maximum strain and displacement of the pipe are significantly reduced. This decreasing trend tends to zero after specific distances (according to environmental conditions, pipes, and explosions); here, it has occurred after 5 meters.

(5) The internal pressure of the pipe and the coefficient of interaction friction between the soil and the pipe have a negligible effect on the response of the pipe.

(6) The larger the diameter and thickness of the pipe, the better the performance of the pipe with increasing the cross-sectional moment of inertia. The relation between the results and the conversions in these parameters is approximately linear.

(7) By increasing the coefficient of internal friction of the soil, the maximum strain and displacement of the pipe decrease. The effectiveness of this parameter is significant compared to other parameters.

(8) While the specific gravity of the soil increases, the maximum pipe stress and strain decrease considerably, but there is no noticeable change in the maximum pipe displacement.

(9) According to the previous results, in the case of buried shell structures, such as pipes, it can be understood that their performance is more affected by the deformation of the structure (such as pipe 
bending) than the effects of soil-structure interaction.

\section{Data Availability}

The data used to support the findings of this study are available from the corresponding author upon reasonable request.

\section{Conflicts of Interest}

The authors declare that there are no conflicts of interest regarding the publication of this paper.

\section{Acknowledgments}

The authors of this article are grateful for the valuable guidance of Mr. Abbas Aghasi.

\section{References}

[1] A. S. Abedi, N. Hataf, and A. Ghahramani, "Analytical solution of the dynamic response of buried pipelines under blast wave," International Journal of Rock Mechanics and Mining Sciences, vol. 88, pp. 301-306, 2016.

[2] K. Wang, Z. Liu, X. Qian, and Y. He, "Dynamic characteristics and damage recognition of blast-induced ground vibration for natural gas transmission pipeline and its integrated systems," Mechanical Systems and Signal Processing, vol. 136, Article ID 106472, 2020.

[3] C. Shi, Q. Zhao, M. Lei, and M. Peng, "Vibration velocity control standard of buried pipeline under blast loading of adjacent tunnel," Soils and Foundations, vol. 59, no. 6, pp. 2195-2205, 2019.

[4] V. R. Kiran and P. Manoj, "Mechanical analysis of buried gas pipe line of different grades of steel at a depth under the influence of sub-surface blast loading," 2018.

[5] K. Song, Y. Long, C. Ji, F. Gao, and H. Chen, "Experimental and numerical studies on the deformation and tearing of X70 pipelines subjected to localized blast loading," Thin-Walled Structures, vol. 107, pp. 156-168, 2016.

[6] L. Ni, J. Lang, and L. Chen, "Numerical simulation on the dynamic response of submarine pipelines under blast loading," Oil \& Gas Storage and Transportation, vol. 2, p. 17, 2018.

[7] S. Stanković, V. Škrlec, and M. Dobrilović, "Influence of blastinduced ground vibrations on buried transmission pipelines," in Proceedings of the Seventh International Conference on Advances in Civil, Structural and Mechanical EngineeringCSM, Rome, Italy, December 2018.

[8] J. Zhang, L. Zhang, and Z. Liang, "Buckling failure of a buried pipeline subjected to ground explosions," Process Safety and Environmental Protection, vol. 114, pp. 36-47, 2018.

[9] M. Bai, X. Xu, H. Yang et al., "Safety evaluations of a largescale facility under blast loading," Journal of Vibroengineering, vol. 22, no. 4, pp. 849-867, 2020.

[10] L. Chernin, M. Vilnay, and I. Shufrin, "Blast dynamics of beam-columns via analytical approach," International Journal of Mechanical Sciences, vol. 106, pp. 331-345, 2016.

[11] H. Jiang, T. Xu, and D. Zhao, "Dynamic response and limit analysis of buried high-pressure gas pipeline under blasting load based on the Hamilton principle," Journal of Vibroengineering, vol. 19, no. 1, pp. 376-393, 2017.
[12] E. Giannaros, T. Kotzakolios, and V. Kostopoulos, "Blast response of composite pipeline structure using finite element techniques," Journal of Composite Materials, vol. 50, no. 25, pp. 3459-3476, 2016.

[13] Y.-G. Wang, C. C. Liao, and J. H. Wang, "Numerical investigation of pore pressure effect on blast-induced pipelineseabed interaction," Applied Ocean Research, vol. 77, pp. 6168, 2018.

[14] P. Vivek, T. G. Sitharam, G. Jagadeesh, and K. P. J. Reddy, "Response of embedded pipeline to surface blast loading," in Proceedings of the 30th International Symposium On Shock Waves 1, pp. 749-754, Tel-Aviv, Israel, August 2017.

[15] A. H. I. Sigiuk, "Development of an instantaneous frequency estimation pipeline for compressional and shear wave arrival picking," in Application to Quarry Blast DataUniversity of British Columbia, Vancouver, Canada, 2019.

[16] N. Jiang, T. Gao, C. Zhou, and X. Luo, "Effect of excavation blasting vibration on adjacent buried gas pipeline in a metro tunnel," Tunnelling and Underground Space Technology, vol. 81, pp. 590-601, 2018.

[17] L. Zardasti, N. Yahaya, A. Valipour, A. S. A. Rashid, and N. M. Noor, "Review on the identification of reputation loss indicators in an onshore pipeline explosion event," Journal of Loss Prevention in the Process Industries, vol. 48, pp. 71-86, 2017.

[18] D. Zhong, X. Gong, F. Han, and L. Li, "Monitoring the dynamic response of a buried polyethylene pipe to a blast wave: an experimental study," Applied Sciences, vol. 9, no. 8, p. 1663, 2019.

[19] P. Vivek and T. G. Sitharam, "Response of embedded structures in granular material to air-blast wave loading," in Granular Materials Under Shock and Blast LoadingSpringer, Berlin, Germany, 2020.

[20] K. Wang, T. Shi, Y. He, M. Li, and X. Qian, "Case analysis and CFD numerical study on gas explosion and damage processing caused by aging urban subsurface pipeline failures," Engineering Failure Analysis, vol. 97, pp. 201-219, 2019.

[21] P. Vazouras, S. A. Karamanos, and P. Dakoulas, "Mechanical behavior of buried steel pipes crossing active strike-slip faults," Soil Dynamics and Earthquake Engineering, vol. 41, pp. 164-180, 2012.

[22] S. M. S. Kolbadi, N. Hassani, and M. Safi, "Numerical evaluation on improvement performance of waved connection to reduce damage on buried gas pipeline," Shock and Vibration, vol. 2020, Article ID 6680384, 17 pages, 2020.

[23] M. Mirtaheri, S. Sehat, and M. Nazeryan, "Improving the behavior of buckling restrained braces through obtaining optimum steel core length," Structural Engineering and Mechanics, vol. 65, pp. 401-408, 2018.

[24] R. K. Mohammadi, M. Mirjalaly, M. Mirtaheri, and M. Nazeryan, "Comparison between uniform deformation method and Genetic Algorithm for optimizing mechanical properties of dampers," Earthquakes and Structures, vol. 14, pp. 001-010, 2018.

[25] S. M. Seyed Kolbadi, H. Piri, A. Keyhani, S. M. Seyed-Kolbadi, and M. Mirtaheri, "Nonlinear seismic performance evaluation of flexural slotted connection using endurance time method," Shock And Vibration, vol. 2020, Article ID 8842230, , 2020.

[26] S. M. S. Kolbadi and H. Davoodian, "Evaluation of nonlinear behavior of reinforced concrete frames by explosive dynamic loading using finite element method," Civil Engineering Journal, vol. 3, pp. 12-20, 2017.

[27] S. Mohammad, S. Kolbadi, N. Hassani, S. M. S. Kolbadi, and M. R. Shiravand, "Effect of ground motions on nonlinear seismic behavior of corroded buried gas pipeline," American Journal of Civil Engineering, vol. 3, pp. 9-13, 2015. 